
䙮
Contents lists available at www.ijpba.in
International Journal of Pharmaceutical and Biological Science Archive
PubMed (National Library of Medicine ID: 101738825)
Index Copernicus Value 2017: 71.80
Volume 7 Issue 2; March-April; 2019; Page No. 117-160

\title{
FORMULATION AND EVALUATION OF CONTROLLED RELEASE OSMOTIC TABLET OF CARVEDILOL PHOSPHATE
}

\author{
Mr. Sunny Sureshbhai Sharma \\ PG Research Scholar, Department of Pharmaceutics, Sharda School of Pharmacy, Pethapur, \\ Gandhinagar, Gujarat \\ Mr. Anil G Raval \\ Assistant Professor, Department of Pharmaceutics, Sharda School of Pharmacy, Pethapur, \\ Gandhinagar, Gujarat
}

\begin{abstract}
Carvedilol Phosphate Osmotic Tablets were prepared using a Direct Compression approach. A mixture of osmogens i.e. $\mathrm{NaCl}$ and Mannitol was used to achieve a desired osmotic pressure in the tablets which were then coated with Cellulose Acetate polymer with PEG as a plasticizer and Povidone K30 as a pore former. Early screening batches showed drastic effect of osmogens and pore former, as well as \% weight gain on drug release of the tablets. The prepared tablets were evaluated for Weight variation, Thickness, Hardness, Dissolution, and the final optimized formulation was exposed to Accelerated Stability Study. A full factorial statistical optimization was carried out on the best optimized formulation to establish the design space for selected factors i.e., $\mathrm{NaCl}$ and Povidone $\mathrm{K} 30$ against Response Dissolution. A significant effect of both factors was found on Dissolution rate, which justifies the use and rationale of the excipients
\end{abstract}

Key Words: Carvedilol Phosphate, Osmotic Tablets, Direct Compression, $\mathrm{NaCl}$, Mannitol, Cellulose Acetate.

1. INTRODUCTION

\subsection{Introduction of Drug Delivery System}

\subsubsection{Osmotic Drug Delivery Systems: ${ }^{(1,2)}$}

Customary medication conveyance frameworks have little authority over their medication discharge and no influence over the fruitful fixation at the objective site. This sort of dosing example may result in ceaselessly changing, irregular plasma fixations. Medications can be conveyed in a controlled model over an extensive stretch of time by the controlled or adjusted discharge tranquilizes conveyance frameworks. They contain dose shapes for oral and transdermal association and infuse capable and implantable frameworks. For the majority of medications, oral course stays as the most agreeable course of organization. Distinct kind of atoms may have low oral bioavailability due to dissolvability or penetrability confinements.

Improvement of an all-encompassing discharge dose shape additionally requires sensible ingestion all through the gastro-intestinal tract (GIT). Among the possible methods to enhance the bioavailability of these medications creation osmotic medication conveyance framework is the most suitable one. Osmotic medication conveyance frameworks (OSCDDS) release the medication with the zero request energy which does not rely upon the underlying focus and the physiological elements of GIT.

- Concept of Osmosis:- ${ }^{(3)}$

$\rightarrow$ Osmolarity: - Osmolarity is the number of osmoses per liter of solution.

$\rightarrow$ Osmolality:- Osmolality is the number of osmoses per Kg of water.

$\rightarrow$ Osmosis: - Osmosis refers to the process of association of solvent molecules from lesser concentration to higher concentration across a semi permeable membrane.

$\rightarrow$ Osmotic Pressure: - Osmotic weight is a colligative property of an answer in which the size of osmotic weight of the arrangement is self overseeing on the quantity of independent elements of solute present in 
the arrangement. Osmotic weight created because of imbibitions of liquid from outside air into the measurements frame manages the conveyance of medication from osmotic gadget. Speed of medication discharge from osmotic siphon is straightly relative to the osmotic weight created because of imbibitions of liquids by Osmogens.

\section{$\rightarrow$ Principles of Osmosis :- ${ }^{(4)}$}

The main data of an osmotic impact dated to Abbenollet (1748). Be that as it may, Pfeffer acquired the principal quantitative estimation in 1877. In Pfeffer examination, a film permeable to water however restricting to sugar is utilized to isolate a sugar arrangement from unadulterated water. A stream of water at that point happens into the sugar arrangement that can't be stopped until a weight $\pi$ is useful to the sugar arrangement. Pfeffer demonstrated that this weight, the osmotic weight $\pi$ of the sugar arrangement is straightly in respect to the arrangement fixation and the total temperature. Inside couple of years, Vant Hoff had demonstrated the likeness between these outcomes and perfect gas laws by the express:

$\pi=\varnothing \mathrm{CRT}$

Where,

$\varnothing=$ Osmotic pressure,

$\pi=$ osmotic coefficient,

$\mathrm{C}=$ molar absorption,

$\mathrm{R}=$ gas constant,

$\mathrm{T}=$ Absolute temperature.

Osmotic weight is a colligative property, which relies upon grouping of solute that adds to osmotic weight. Arrangements of disparate fixations having the comparable solute and dissolvable framework reveal an osmotic weight with respect to their focuses. Consequently a relentless osmotic weight and there by a steady flood of water can be accomplished by an osmotic conveyance framework that results a consistent zero request discharge rate of medication. Osmotic weight for concentrated arrangement of dissolvable solutes ordinarily utilized in controlled discharge definition are essentially high running from $30 \mathrm{~atm}$ for sodium phosphate up to $500 \mathrm{~atm}$ for a lactose-fructose blend, as their osmotic weight can produce high water stream crosswise over semi penetrable film. The osmotic water course through a film is given by the condition;

$d v \backslash d t=A Q \Delta \pi \backslash L$

Where,

$\mathrm{dv} \backslash \mathrm{dt}=$ water stream across the membrane of area $\mathrm{A}$ in $\mathrm{cm}^{2}$,

$L=$ thickness,

$\mathrm{Q}=$ permeability,

$\Delta \pi=$ the osmotic pressure dissimilarity between the two solutions on either side of the membrane.

This equation is strictly for totally perm discriminating membrane that is membrane porous to water but completely impermeable to osmotic agent.

- Advantages:- ${ }^{(5)}$

$\checkmark$ They typically give a zero order release summary after an initial lag.

$\checkmark$ Deliveries may be belated or pulsed if preferred.

$\checkmark$ Drug discharge is free of gastric $\mathrm{pH}$ and hydrodynamic state.

$\checkmark$ They are well unspoken and characterized. 
$\checkmark \quad$ The release mechanisms are not dependent on drug.

$\checkmark \quad$ A high quantity of in-vitro and in-vivo correlation (IVIVC) is obtained in osmotic systems.

$\checkmark$ Superior release rates are promising with osmotic systems compared with predictable diffused controlled drug delivery systems.

$\checkmark \quad$ The release from osmotic systems is modestly affected by the presence of food in gastro intestinal tract.

$\checkmark$ The release rate of osmotic systems is highly expected and can be planned by modulating the release control parameters.

- Disadvantages :- ${ }^{(6)}$

$\checkmark$ Special equipment is necessary for making an orifice in the system.

$\checkmark \quad$ It may cause irritation or ulcer due to release of soaked solution of drug.

$\checkmark$ Dose dumping.

$\checkmark$ Retrieval therapy is not possible in the case of unpredicted adverse events.

$\checkmark$ Luxurious.

$\checkmark \quad$ If the coating process is not well controlled there is a danger of film defects, which outcome in dose discarding.

$\checkmark$ Size hole is dangerous.

- Limitations :- ${ }^{(7)}$

$\checkmark \quad$ It may cause frustration or ulcer due to release of soaked solution of drug.

$\checkmark$ Extraordinary equipment is necessary for creating the orifice in the system.

$\checkmark$ Habitation time of the system in the body varies with the gastric motility and food eating.

- Basic Components of Osmotic Systems:- ${ }^{(8)}$

\section{a) Drug:}

Medication which have short organic half-life (2-6 hrs), exceptionally strong and which is utilized for drawn out treatment are perfect contender for osmotic frameworks. Different medication hopefuls, for example, Diltiazem $\mathrm{HCl}$, Carbamazepine, Metoprolol, Oxprenolol, Nifedipine, Glipizide, verapamil and so on are planned as osmotic conveyance.

\section{b) Osmotic agent:}

Osmotic operators are basic element of the osmotid detailing. Osmotic segments typically are ionic mixes comprising of either inorganic salts hydrophilic polymers or sugars. For the most part blends of osmotic operators are utilized to accomplish ideal osmotic weight inside the framework. Distinctive sort of osmogents can be utilized for such frameworks are classified as water-solvent salts of inorganic acids like magnesium chloride or sulfate; lithium, sodium, or potassium chloride; sodium or potassium hydrogen phosphate; watersoluble salts of natural acids like sodium and potassium acetic acid derivation, magnesium succinate, sodium benzoate, sodium citrate, sodium ascorbate; Carbohydrates like mannose, sucrose, maltose lactose; water-dissolvable amino acids and natural polymeric osmogents, and so on. Polymeric osmogents are mostly utilized in the creation of osmotically controlled medication conveyance frameworks and other altered gadgets for controlled arrival of moderately insoluble medications. Osmotic weights for concentrated arrangement of solvent solutes usually utilized in controlled discharge plans are amazingly high, going from $30 \mathrm{~atm}$ for sodium phosphate up to $500 \mathrm{~atm}$ for a lactose-fructose blend. These osmotic weights can create high water streams crosswise over semipermeable films.

\section{c) Semipermeable membrane:}

An imperative piece of the osmotic medication conveyance framework is the Semipermeable film. In this manner, the polymeric layer choice is the way to osmotic conveyance detailing. Any polymer that is penetrable to water however impermeable to solute (tranquilize and excipients) can be utilized as a covering material in osmotic gadgets. e. g. Cellulose esters like cellulose acetic acid derivation, cellulose acetic acid derivation butyrate, cellulose triacetate and ethyl cellulose and Eudragit. Cellulose acetic acid derivation is 
usually utilized for semi porous layer. It is accessible in various acetyl content like $32 \%, 38 \%$ are broadly utilized.

The membrane must possess certain performance criteria such as:

1. The membrane should be stable to both outside and inside environments of the device.

2. The material must possess sufficient wet strength (10-5 Psi) and wet modules so (10-5 Psi) as to retain its dimensional integrity during the operational lifetime of the device.

3. It must exhibit sufficient water permeability so as to attain water flux rates (dv/dt) in the desired range. The water vapour transmission rates can be used to estimate water flux rates.

4. It must be sufficiently rigid so as to withstand the pressure within the device, to retain its dimensional integrity during the operational lifetime of the device.

5. The reflection coefficient or "leakiness" of the osmotic agents should approach the limiting value of unity. But polymer membranes must be more permeable to water.

6. It should also be relatively impermeable to the contents of dispenser so that osmogent is not lost by diffusion across the membrane.

7. It should be non- swelling.

8. It should be biocompatible.

d) Plasticizers:

Plasticizers utilized in covering film likewise have a noteworthy significance in the plan of osmotic frameworks. It brings down the temperature of the second request stage change of the divider or the versatile modules of the divider and furthermore builds the usefulness. They can change visco-versatile conduct of polymers and these progressions may influence the penetrability of the polymeric movies.

Some of the plasticizers used are as below:

1. Polyethylene glycols

2. Ethylene glycol monoacetate; and diacetate- for low permeability

3. Tri ethyl citrate

4. Diethyl tartarate or Diacetin-for more permeable films

5. dialkylphthalate, Trioctylphosphate,

6. Alkyl adipates, Acetate, Propionate, Glycolate.

\section{e) Coating Solvent}

For making polymeric layer, reasonable dissolvable ought to be utilized. There are different natural and inorganic dissolvable are accessible. Solvents ought not be poisonous, ought not be change the substance idea of polymer, ought to be solubilise to polymer totally. A few precedents of solvents are $\mathrm{CH} 3$ )2CO, isopropyl liquor, ethanol, methanol, carbon tetrachloride, water, ethyl acetic acid derivation, cyclohexane, butyl liquor. The blend of dissolvable like, acetoneethanol, methylene chloride-methanol, acetoneisopropyl liquor, $\mathrm{CH} 3) 2 \mathrm{CO}$ water, methylene choloride-methanol-water.

- Evaluation Parameters of Oral Osmotic Drug Delivery System: ${ }^{(9)}$

\section{A. Evaluation of Powder:}

$\rightarrow$ Weight of powder

$\rightarrow$ Bulk density 
$\rightarrow$ Tapped density

$\rightarrow$ Carr's index

$\rightarrow$ Angle of repose

B. Evaluation of Osmotic tablet:

$\rightarrow$ Hardness

$\rightarrow$ Thickness

$\rightarrow$ Friability

$\rightarrow$ Weight uniformity

$\rightarrow$ Stability Studies

$\rightarrow$ Effect of osmotic pressure

$\rightarrow$ Effect of $\mathrm{pH}$ on drug release

$\rightarrow$ Measurement of orifice diameter

$\rightarrow \quad$ In vitro drug release

Table 1: Marketed Products Based on Osmotic Principles

\begin{tabular}{|l|l|}
\hline Brand Name & API \\
\hline $\begin{array}{l}\text { Elementary osmotic pump } \\
\text { (ALZA Corporation) }\end{array}$ & $\begin{array}{l}\text { Once daily osmotic tablet with solid active } \\
\text { agents }\end{array}$ \\
\hline Efidac $24^{\oplus}$ & Chlorpheniraamine \\
\hline Volmax & Albuterol \\
\hline Acutrim ${ }^{\oplus}$ & Phenylpropanolamine \\
\hline Sudafed $24^{\oplus}$ & Pseudoephedrine \\
\hline $\begin{array}{l}\text { Push-pull osmotic delivery system } \\
\text { (ALZA Corporation) }\end{array}$ & $\begin{array}{l}\text { Multilayered tablet for drugs with low to high } \\
\text { solubility }\end{array}$ \\
\hline Concerta & Methylphenidate HCl \\
\hline Covera HS & Verapamil HCl \\
\hline Glucotrol XL & Glipizide \\
\hline Ditropan XL & Oxybutynin chloride \\
\hline
\end{tabular}

\section{- Classification of Oral Osmotic Pump: ${ }^{(10)}$}

As oral course is the most prominent course of organization, a large portion of the osmotic frameworks are created as oral medication conveyance. It is conceivable to convey dynamic operator at zero-arrange 
discharge rate, autonomous of gastric $\mathrm{pH}$ and hydrodynamic conditions with these osmotically controlled medication conveyance frameworks.

Types of oral osmotic pumps:

1. Single chamber osmotic pump: Elementary osmotic pump

2. Multi chamber osmotic pump: Push pull osmotic pump, Osmotic pump with nonexpanding second chamber

Specific types: Controlled porosity osmotic pump, Osmotic bursting osmotic pump, Liquid OROS, Delayed Delivery Osmotic device, Telescopic capsule, Oros CT (colon targeting), Sandwiched oral therapeutic system, Monolithic osmotic system and OSMAT

\subsection{Introduction of Disease}

- Congestive Heart Failure:- ${ }^{(11)}$

\section{Definition:-}

Heart disappointment, now and again known as congestive heart disappointment, happens when your heart muscle doesn't siphon blood and also it should. Certain conditions, for example, limited conduits in your heart (coronary corridor infection) or hypertension, slowly leave your heart excessively powerless or hardened, making it impossible to fill and siphon effectively.

Not all conditions that prompt heart disappointment can be turned around, yet medications can enhance the signs and manifestations of heart disappointment and help you live more. Way of life changes - , for example, working out, diminishing sodium in your eating regimen, overseeing pressure and getting thinner - can enhance your personal satisfaction.

One approach to avoid heart disappointment is to anticipate and control conditions that reason heart disappointment, for example, coronary corridor malady, hypertension, diabetes or stoutness.

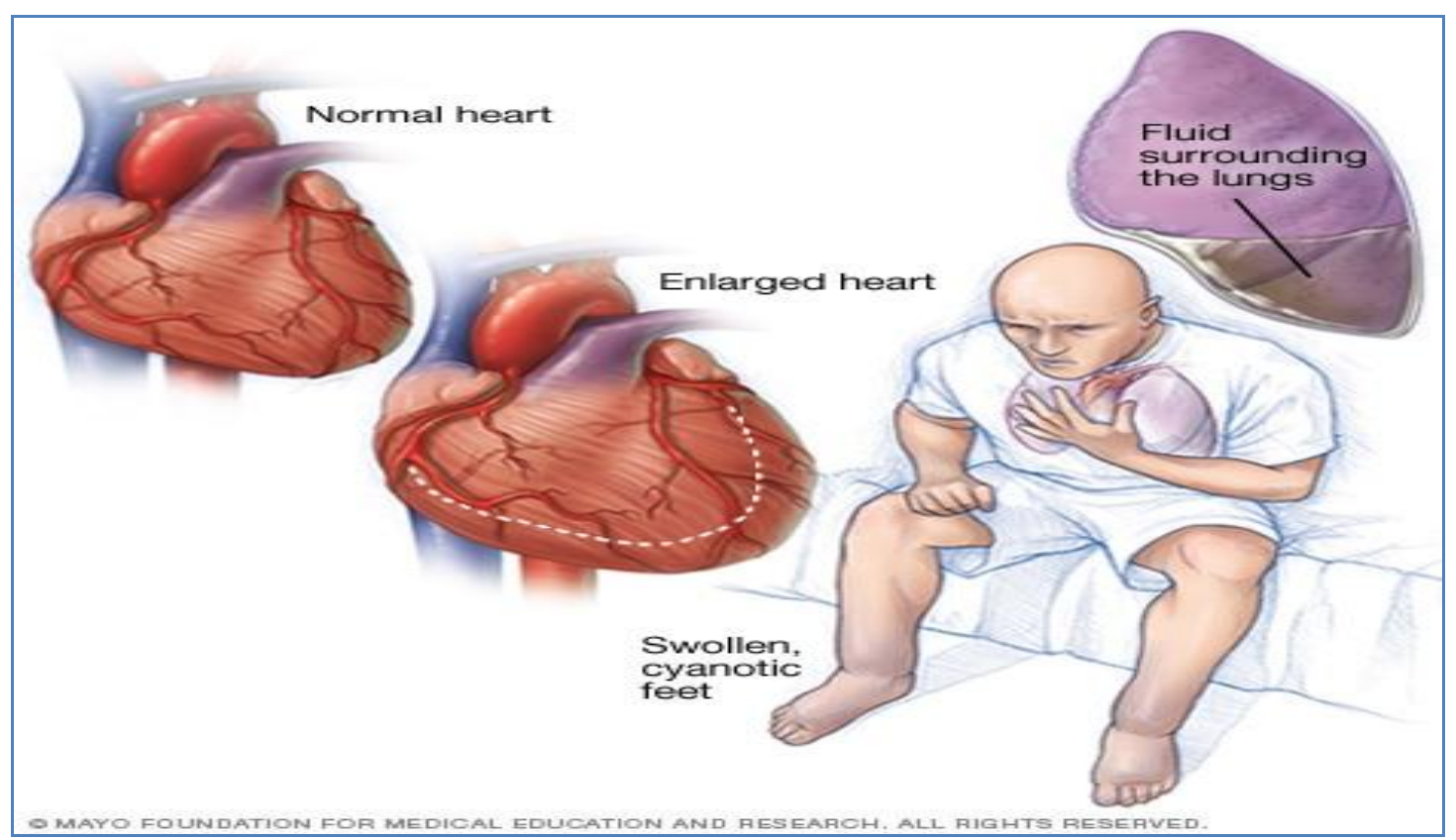

Figure 1 Heart Failure

- Heart failure Symptoms

$\checkmark$ Heart failure can be ongoing (chronic), or your condition may start suddenly (acute). 
$\checkmark$ Heart failure signs and symptoms may include:

$\checkmark$ Shortness of breath (dyspnea) when you exert yourself or when you lie down

$\checkmark \quad$ Fatigue and weakness

$\checkmark$ Swelling (edema) in your legs, ankles and feet

$\checkmark$ Rapid or irregular heartbeat

$\checkmark$ Reduced ability to exercise

$\checkmark$ Persistent cough or wheezing with white or pink blood-tinged phlegm

$\checkmark$ Increased need to urinate at night

$\checkmark$ Swelling of your abdomen (ascites)

$\checkmark$ Very rapid weight gain from fluid retention

$\checkmark \quad$ Lack of appetite and nausea

$\checkmark$ Difficulty concentrating or decreased alertness

$\checkmark$ Sudden, severe shortness of breath and coughing up pink, foamy mucus

$\checkmark$ Chest pain if your heart failure is caused by a heart attack

\subsection{Introduction of Drug}

- Carvedilol Phosphate:-(12-17)

Table 2: Drug Information

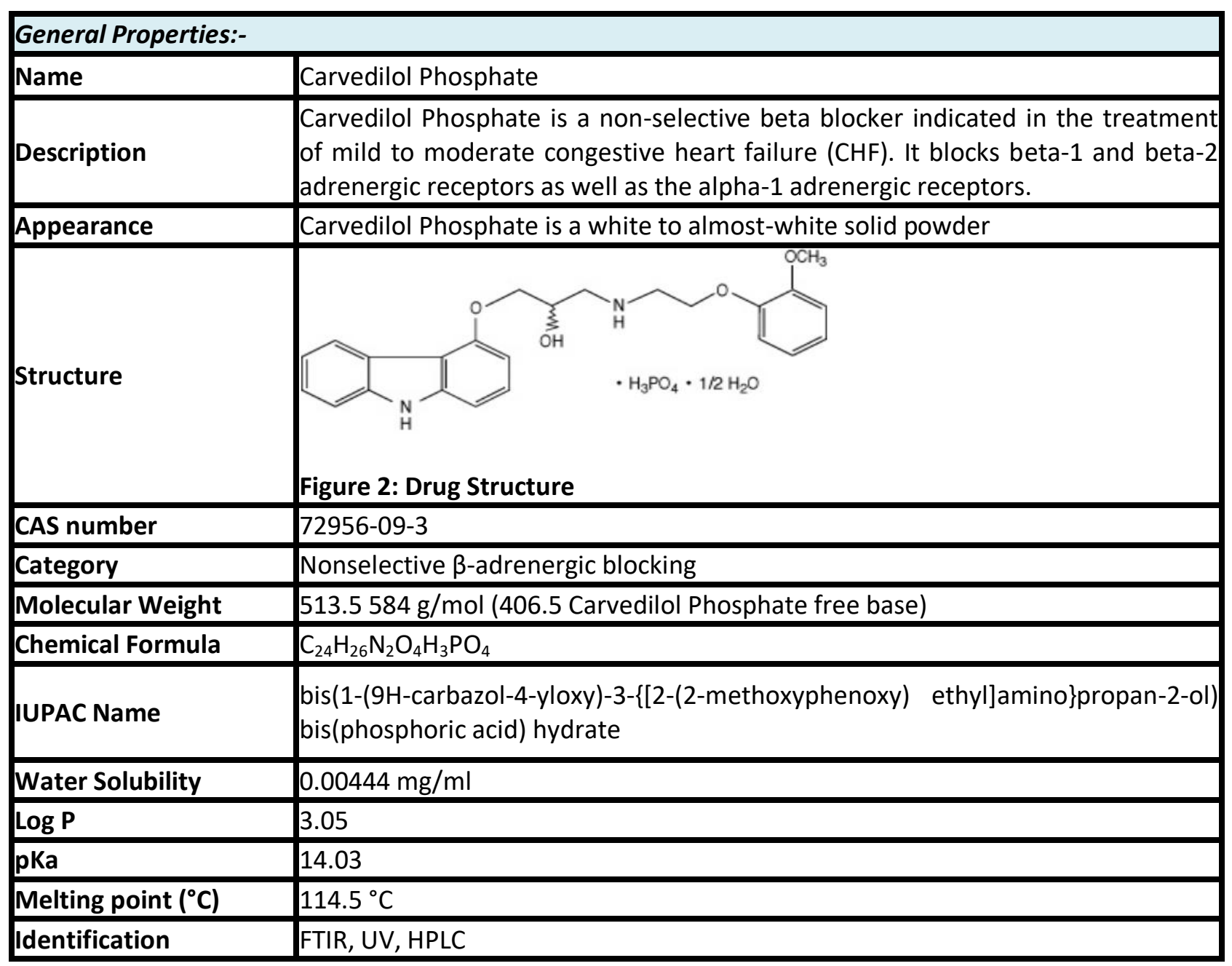




\begin{tabular}{|l|l|}
\hline BCS Class & II \\
\hline Dose & $3.125 / 6.25 / 12.5 / 25 \mathrm{mg}$ \\
\hline Pharmacokinetic Properties:- & $\begin{array}{l}\text { Carvedilol Phosphate is rapidly and extensively absorbed following oral } \\
\text { administration, with an absolute bioavailability of approximately 25\% to 35\% due } \\
\text { to a significant degree of first-pass metabolism. }\end{array}$ \\
\hline Absorption & $25-35 \%$ \\
\hline Bioavailability & $98 \%$ \\
\hline Protein binding & Hepatic \\
\hline Metabolism & 7 hours \\
\hline Half life & $\begin{array}{l}\text { Carvedilol Phosphate is extensively metabolized. Less than 2\% of the dose was } \\
\text { excreted unchanged in the urine. Carvedilol Phosphate is metabolized primarily by } \\
\text { aromatic ring oxidation and glucuronidation. }\end{array}$ \\
\hline Excretion & $\begin{array}{l}\text { For the treatment of mild or moderate (NYHA class II or III) heart failure of } \\
\text { ischemic or cardiomyopathic origin. }\end{array}$ \\
\hline Pharmacological Properties:- \\
\hline Indication & $\begin{array}{l}\text { Carvedilol Phosphate is a racemic mixture in which nonselective beta- } \\
\text { adrenoreceptor blocking activity is present in the S (-) enantiomer and alpha- } \\
\text { adrenergic blocking activity is present in both R(+) and S(-) enantiomers at equal } \\
\text { potency. }\end{array}$ \\
\hline Mechanism of action
\end{tabular}




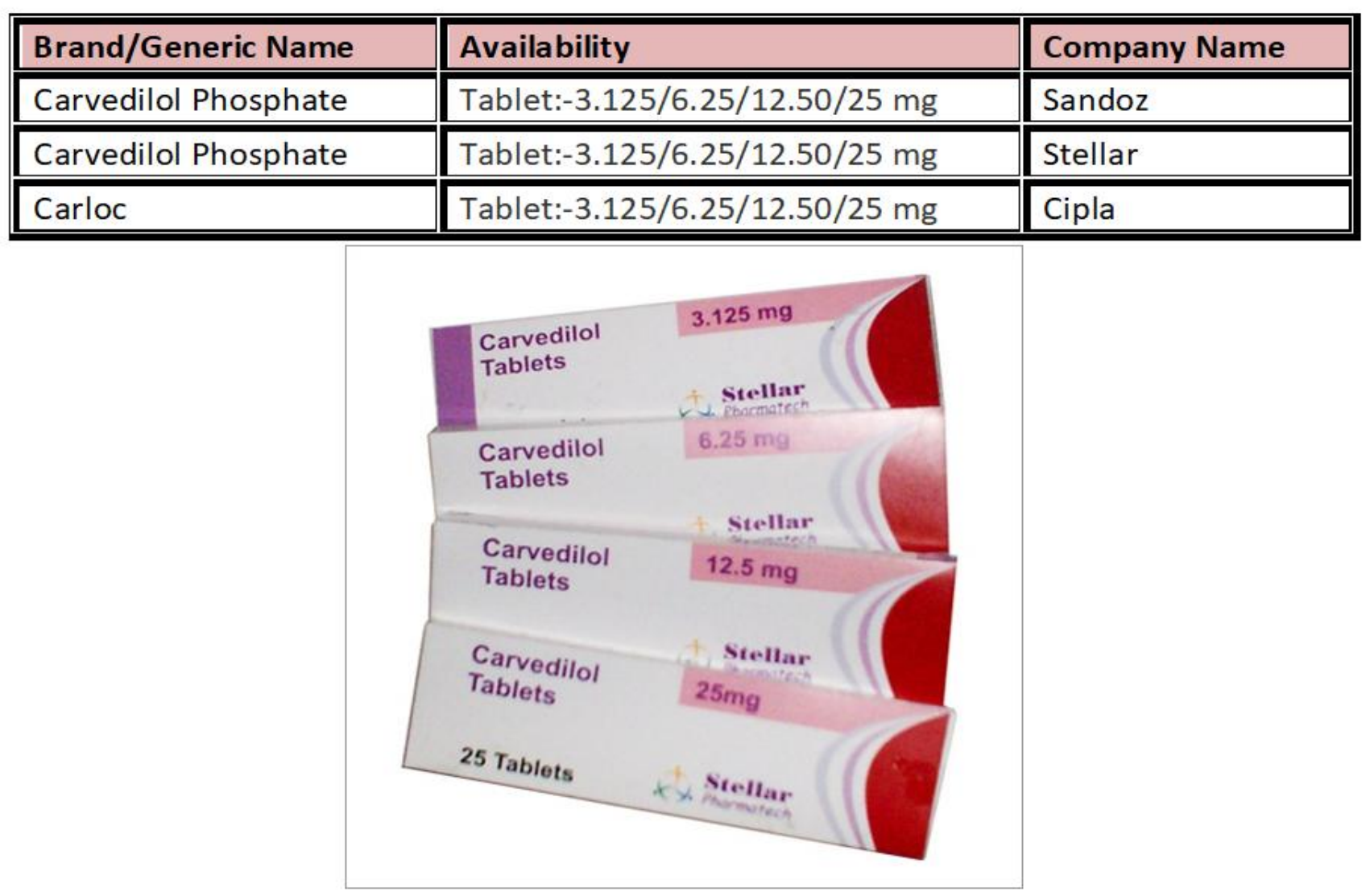

Figure 3: Marketed Formulation

\subsection{Introduction to Excipients}

\subsubsection{MANNITOL}

Synonym: Mannogem, Pearlitol

Description: Mannitol occurs as a white, odorless, crystalline powder, or freeflowing granules. It has a sweet taste, approximately as sweet as glucose and half as sweet as sucrose, and imparts a cooling sensation in the mouth. Microscopically, it appears as orthorhombic needles when crystallized from alcohol. Mannitol shows polymorphism.

Functional Category: Diluent; plasticizer; sweetening agent; tablet and capsule diluent; therapeutic agent; tonicity agent.

Solubility: Insoluble in ether, 1 part soluble in 5.5 parts of water

Stability \& Storage: Mannitol is stable in the dry state and in aqueous solutions. The bulk material should be stored in a well-closed container in a cool, dry place

Safety: Mannitol is a naturally occurring sugar alcohol found in animals and plants; it is present in small quantities in almost all vegetables. Laxative effects may occur if mannitol is consumed orally in large quantities.

\subsubsection{SODIUM CHLORIDE}

Synonym: Saline salt, Rock Salt, Sea Salt, Table Salt. 
Description: Sodium chloride occurs as a white crystalline powder or colorless crystals; it has a saline taste. The crystal lattice is a face-centered cubic structure. Solid sodium chloride contains no water of crystallization although, below $0 \mathrm{C}$, salt may crystallize as a dehydrate.

Functional Category: Tablet and capsule diluent; tonicity agent.

Solubility: Soluble in water, ethanol, and 1 part in 10 parts glycerin

Stability \& Storage: Aqueous sodium chloride solutions are stable but may cause the separation of glass particles from certain types of glass containers. Aqueous solutions may be sterilized by autoclaving or filtration. The solid material is stable and should be stored in a well-closed container, in a cool, dry place. It has been shown that the compaction characteristics and the mechanical properties of tablets are influenced by the relative humidity of the storage conditions under which sodium chloride was kept.

Safety: maintaining the osmotic tension of blood and tissues. About 5-12 g of sodium chloride is consumed daily, in the normal adult diet, and a corresponding amount is excreted in the urine. As an excipient, sodium chloride may be regarded as an essentially nontoxic and nonirritant material.

\subsubsection{MICROCRYSTALLINECELLULOSE}

Synonym: Avicel PH, Tabulose, Emocel, Vivapur.

Description: Purified, partially depolymerised cellulose that occurs as a white,

odourless, tasteless, crystalline powder composed of porous particles.

Functional Category: Adsorbent; suspending agent; tablet \& capsule diluent; tablet

disintegrant.

Solubility: Practically Insoluble in water.

Stability \& Storage: Stored in well closed container in a cool and dry place.

Safety: It is widely used in oral formulations and food products and generally

regarded as a non-toxic and non-irritant material.

\subsubsection{PREGELATINIZED STARCH}

Synonym: Lycatab, Compressible Starch

Functional Category: Tablet and capsule diluent; tablet and capsule disintegrant; tablet binder.

Solubility: Practically insoluble in organic solvents. Slightly soluble to soluble in cold water, depending upon the degree of pregelatinization. Pastes can be prepared by sifting the pregelatinized starch into stirred, cold water. Cold-water-soluble matter for partially pregelatinized starch is $10-20 \%$.

Stability and Storage: Pregelatinized starch is a stable but hygroscopic material, which should be stored in a well-closed container in a cool, dry place.

Safety: Pregelatinized starch and starch are widely used in oral solid-dosage formulations. Pregelatinized starch is generally regarded as a nontoxic and nonirritant excipient. However, oral consumption of large amounts of pregelatinized starch may be harmful.

\subsubsection{LOW-SUBSTITUTED HYDROXYPROPYL CELLULOSE}

Synonym: Hyprolose low substituted, L-HPC

Description: Low-substituted hydroxypropyl cellulose occurs as a white to yellowish white powder or granules. It is tasteless, odorless or has a slight characteristic odor.

Functional Category: Tablet and capsule disintegrant; tablet binder. 
Solubility: Practically insoluble in ethanol (95\%) and in ether. Dissolves in a solution of sodium hydroxide (1 in $10)$ and produces a viscous solution. Insoluble, but swells in water.

Stability \& Storage: Low-substituted hydroxypropyl cellulose is a stable, though hygroscopic, material. The powder should be stored in a well closed container.

Safety: Low-substituted hydroxypropyl cellulose is generally regarded as a

nontoxic and nonirritant material.

\subsubsection{TALC}

Synonym: Altac, hydrous magnesium silicate, magnesium hydroxide metasilicate

Description: Talc is a very fine, white to grayish-white, odorless, impalpable, unctuous, crystalline powder. It adheres readily to the skin and is soft to the touch and free from grittiness.

Functional Category: Anticaking agent; glidant; tablet and capsule diluent; tablet and capsule lubricant.

Solubility: Practically insoluble in dilute acids and alkalis, organic solvents, and water.

Stability \& Storage: Talc is a stable material and may be sterilized by heating at $160 \mathrm{C}$ for not less than 1 hour. It may also be sterilized by exposure to ethylene oxide or gamma irradiation. Talc should be stored in a wellclosed container in a cool, dry place.

Safety: Talc is used mainly in tablet and capsule formulations. Talc is not absorbed systemically following oral ingestion and is therefore regarded as an essentially nontoxic material.

\subsubsection{MAGNESIUM STEARATE}

Synonyms: Stearic acid magnesium salt, magnesium octadecanoate.

Molecular Weight: $125 \mathrm{~g} / \mathrm{mol}$

Description: Magnesium stearate is a fine, white, precipitated, milled, impalpable powder of low bulk density, having a faint, characteristic odour and taste. The powder

is greasy to touch and readily adheres to skin.

\section{Pharmaceutical Uses:}

Magnesium stearate is widely used in cosmetics, foods and pharmaceutical formulations. It is primarily used as lubricant in capsule and tablet manufacturing at concentration between $0.25-5.0 \% \mathrm{w} / \mathrm{w}$.

Solubility: It is practically insoluble in ethanol, ethanol (95\%), ether and water, slightly soluble in warm benzene and warm ethanol (95\%).

\subsubsection{CELLULOSE ACETATE}

Synonym: Acetic acid cellulose ester, acetyl cellulose

Description: Cellulose acetate occurs as a hygroscopic white to off-white, freeflowing powder, pellet, or flake. It is tasteless and odorless, or may have a slight odor of acetic acid.

Functional Category: Coating agent; extended-release agent; tablet and capsule diluent.

Solubility: The solubility of cellulose acetate is greatly influenced by the level of acetyl groups present. In general, cellulose acetates are soluble in acetone-water blends of varying ratios, dichloromethane- ethanol blends, dimethyl formamide, and dioxane.

Stability \& Storage: Cellulose acetate is stable if stored in a well-closed container in a cool, dry place. Cellulose acetate hydrolyzes slowly under prolonged adverse conditions such as high temperature and humidity, with a resultant increase in free acid content and odor of acetic acid. 
Safety: Cellulose acetate is widely used in oral pharmaceutical products and is generally regarded as a nontoxic and nonirritant material

\subsubsection{POLY ETHYLENE GLYCOL}

Synonym: Macrogol, Carbowax.

Description: The USP32-NF27 describes polyethylene glycol as being an addition polymer of ethylene oxide and water. Polyethylene glycol grades 200-600 are liquids; grades 1000 and above are solids at ambient temperatures. Liquid grades (PEG 200-600) occur as clear, colorless or slightly yellow-colored, viscous liquids. They have a slight but characteristic odor and a bitter, slightly burning taste. PEG 600 can occur as a solid at ambient temperatures.

Functional Category: Ointment base; plasticizer; solvent; suppository base; tablet and capsule lubricant.

Solubility: All grades of polyethylene glycol are soluble in water and miscible in all proportions with other polyethylene glycols (after melting, if necessary). Aqueous solutions of higher molecular- weight grades may form gels. Liquid polyethylene glycols are soluble in acetone, alcohols, benzene, glycerin, and glycols. Solid polyethylene glycols are soluble in acetone, dichloromethane, ethanol (95\%), and methanol; they are slightly soluble in aliphatic hydrocarbons and ether, but insoluble in fats, fixed oils, and mineral oil.

Stability \& Storage: Polyethylene glycols should be stored in well-closed containers in a cool, dry place. Stainless steel, aluminum, glass, or lined steel containers are preferred for the storage of liquid grades.

Safety: Polyethylene glycols are widely used in a variety of pharmaceutical formulations. Generally, they are regarded as nontoxic and nonirritant materials.

\subsubsection{POVIDONE}

Synonym: Kollidon; Plasdone, polyvinylpyrrolidone

Description: Povidone occurs as a fine, white to creamy-white colored, odourless or almost odorless, hygroscopic powder.

Functional Category: Tablet binder, Suspending agent, Dissolution enhancer

Solubility: Freely soluble in acids, chloroform, ethanol (95\%), ketones, methanol, and water; practically insoluble in ether, hydrocarbons, and mineral oil.

Stability \& Storage: Povidone darkens to some extent on heating at $150^{\circ} \mathrm{C}$, with a reduction in aqueous solubility. It is stable to a short cycle of heat exposure around $110-130^{\circ} \mathrm{C}$. Aqueous solutions are susceptible to mold growth and require the addition of suitable preservatives. Since the powder is hygroscopic, it should be stored in an airtight container in a cool, dry place.

Safety: Povidone is widely used as an excipient, particularly in oral tablets and solutions. When consumed orally, povidone may be regarded as essentially nontoxic since it is not absorbed from the gastrointestinal tract or mucous membranes. Povidone additionally has no irritant effect on the skin and causes no sensitization.

\section{LITERATURE REVIEW}

\subsection{Review of Literature on Drug Delivery System}

Vidyadhara S et al ${ }^{(18)}$ created osmotic controlled broadened discharge details of verapamil hydrochloride an angiotensin II receptor opponent with hostile to hypertensive action. Verapamil hydrochloride grid tablets were set up by direct pressure process utilizing hydroxypropyl methylcellulose (HPMC) K 15M as polymeric material and mannitol as osmogen at changed fixations. The framework tablets were additionally covered with various creations of ethylcellulose 7cps and polyethylene glycol (PEG) 4000 by container covering strategy. 
Patel H. et al ${ }^{(19)}$ arranged Controlled porosity osmotic tablet of Carvedilol Phosphate and assessed. PVPK 30 utilized as cover. To get wanted disintegration profile different definition parameters like osmogen fixation, level of weight gain and level of pore previous focus were examined. Polysorbate 80 was added as solubilizer to expand its disintegration rate and get medicate discharge up to $24 \mathrm{hr}$ at zero request.

Sandhya $\mathbf{P}$ et al ${ }^{(20)}$ created Controlled discharge details of Glimepiride dependent on osmotic innovation. Plan F9 was chosen as upgraded definition. The impact of various definition variable was concentrated to improve discharge profile. The discharge rate expanded fundamentally as the expansion of osmogen proportion from 1:0.5 to 1:1. The discharge rate expanded essentially with the expansion of grouping of pore framing specialist (PEG-400) as saw from the disintegration profile of the details. In this way sedate discharge was conversely relative to the convergence of osmogen in the center and the measure of pore framing specialists in the covered tablets. The medication discharge from created details was free of $\mathrm{pH}$. The assembling technique was institutionalized and observed to be reproducible. Additionally thinks about are expected to research this plan for its execution in vivo.

Falguni S et al ${ }^{(21)}$ created Controlled discharge osmotic definitions of metoprolol Succinate Core tablets were set up by direct pressure method utilizing fructose and $\mathrm{KCl}$ as osmogens and Avicel PH101 as filler. The center tablets were covered by shower firearm in covering dish and utilized a covering operator cellulose acetic acid derivation ( $2 \% \mathrm{w} / \mathrm{v}$ ) with PEG 400 and PEG 6000 as water dissolvable pore previous and dibutyl-pthalate as plasticizer. The improved detailing was assessed for Compatibility Study by FTIR, In Vitro sedate discharge contemplate by USP-II disintegration mechanical assembly and, quickened soundness think about.

Singla $\mathbf{D}$ et al ${ }^{\text {(22) }}$ created and assessed Extended-discharge definition of tramadol hydrochloride dependent on osmotic innovation. The impact of various definition factors, to be specific level of swellable polymer in the center and film weight gain, was examined. Medication discharge was observed to be influenced by the level of swellable polymer in the center plan. Tramadol discharge was conversely relative to the level of swellable polymer and layer weight. Medication discharge from the created details was free of $\mathrm{pH}$ and fomentation power.

Ramu B et al ${ }^{\text {(23) }}$ created skimming osmotic tablets of Nizatidine, a $\mathrm{H} 2$ receptor opponent, to discharge the medication as two particular heartbeats isolated by a slack time that accomplish plasma fixation profiles changing in a circadian mood mold, for the chronotherapy of ulcer. Skimming osmotic tablets were produced utilizing bubbling technique comprised of three distinct advances viz, arrangement of gliding continued discharge medicate containing tablets pursued by time-slacked ( $4 \mathrm{hrs}$ ) covering with hydrophobic rupturable polymer, ethyl cellulose (EC), lastly pressure covering with quick discharge portion of nizatidine and supporting light layer. Three proportions of Ethyl cellulose to HPMC E15 (32.5:67.5, 50:50, and 67.5:32.5) at three covering levels $(5 \%, 10 \%, 15 \%)$ were utilized to upgrade the slack time ( $4 \mathrm{hrs})$. Carbopol $934 \mathrm{P}$, cross povidone and sodium bicarbonate were utilized in light layer.

Poptani S et al (24) arranged and assessed osmotic controlled medication conveyance arrangement of metoprolol tartarate that can give continous sedate discharge to time of 14 to 15 hours. Before pressure, the readied granules were assessed for stream and pressure attributes. Arranged osmotic medication conveyance framework was assessed for in vitro tranquilize discharge think about. The excipients utilized in this investigation did not change physicochemical properties of the medication, as tried by FTIR. The readied osmotic tablets demonstrated great mechanical properties (hardness and friability) and additionally great in vitro disintegration profile demonstrating the arrival of steady medication for 14 hours. Security ponder was done for advanced cluster (F6) for time of one year in room temperature condition. The aftereffects of steadiness think about demonstrating inconsequential factual distinction when capacity of detailing in one year time frame.

Poptani S et al ${ }^{(25)}$ built up an improved EOP tablets containing consideration complex of Nicardipine Hydrochloride (NH) utilizing focal composite plan. Measure of osmotic specialist (X1) and size of conveyance opening (X2) were chosen as free factors. Plans were set up by direct pressure technique and assessed for \% 
Cumulative Drug Release (\% CDR) at $540 \mathrm{~min}$. as needy factors. Measure of osmotic operator and size of conveyance hole significantly affected $\% \mathrm{CDR}$. The consequences of numerous straight relapse examination uncovered that EOP tablets ought to be readied utilizing an ideal centralization of osmotic specialist and size of conveyance hole to accomplish a zero request sedate discharge.

Wen J et al ${ }^{(26)}$ arranged and upgraded controlled porosity osmotic siphon tablets (CPOPT) for salvianolic corrosive with trial structure strategies including a counterfeit unbiased system (ANN) strategy. Three causal components, i.e., sedate, osmotic weight advancing operator rate, PEG400 content in covering arrangement and covering weight, were assessed dependent on their impacts on medication discharge rate.

Tiegang $X$ et al ${ }^{(26)}$ created time-discharged solid osmotic siphon (TMOP) tablets containing diltiazem hydrochloride (DIL) were set up based on osmotic siphoning instrument. The measurement shapes were covered by Kollidon ${ }^{\circledR}$ CONTROLLED RELEASE-Polyethylene Glycol (PEG) blends by means of pressure covered innovation rather than splash covering strategy to frame the external layer. For more effective plan screening, a three-factor five-level focal composite structure (CCD) was acquainted with investigate the ideal TMOP detailing amid the trials. The in vitro tests demonstrated that the enhanced plan of DIL-stacked TMOP had a slack time of $4 \mathrm{~h}$ and a following 20-h medicate discharge at a surmised zero-arrange rate. In addition, the releasemechanismwas demonstrated dependent on osmotic weight and its profile could be all around recreated by a dynamic condition.

\subsection{Review of Literature on Drug}

Amish $\mathbf{A}$ et al ${ }^{(27)}$ another methodology has been attempted to plan MMTs utilizing a hydrophilic waxy fastener [polyethylene glycol (PEG)- 6-stearate]. Carvedilol Phosphate MMTs were set up by direct pressure technique utilizing diverse mucoadhesive polymers, for example, hydroxypropyl methylcellulose (HPMC), chitosan, and sodium carboxymethyl cellulose ( $\mathrm{Na}-\mathrm{CMC}$ ) at different fixations (extend: $0.5-5 \%$ ) to lessen the flushing activity of salivation and to increment mucosal assimilation. Every one of the definitions were assessed for different physiochemical parameters, and the plans containing the most extreme measure of polymer (F4, F7, and F10) were chosen for further solidness examine.

Ramana B et al ${ }^{(28)}$ detailed and assessed mucoadhesive framework tablets of Carvedilol Phosphate. Grid tablets were set up by direct pressure innovation utilizing diverse sorts and levels of polymers viz. HPMC 100M, HPMC E5, and so on alone and in mixes. Compacted tablets were assessed for thickness, friability, hardness, consistency of weight, and in vitro disintegration thinks about. These investigations demonstrates that the medication discharge can be tweaked by shifting the centralizations of polymers. It was seen that blend of both the polymers in equivalent fixations shows the best discharge profile and ready to continue the medication discharge for 10hrs. Formulataion F11 demonstrates the ideal mucoadhesive quality with medication discharge when contrasted with every other definition in the test. Soundness considers uncovered that every one of the details was observed to be steady under quickened strength contemplates.

Vilas $\mathbf{G}$ et al ${ }^{(29)}$ planned and assessed liquisolid minimal arrangement of Carvedilol Phosphate to give expanded disintegration rate of medication by using PEG400 as the non-unpredictable fluid vehicle.

Sugeuna $\mathbf{V}$ et al ${ }^{\left({ }^{30}\right)}$ Quick dissolving tablets of Carvedilol Phosphate were set up with the reason for conveying the medication straightforwardly into the foundational dissemination and bypassing the hepatic first pass digestion with an associative increment in bioavailability. The dissolvability of Carvedilol Phosphate was enhanced by shaping incorporation complex with cyclodextrin which was then additionally utilized for the detailing of Fast dissolving tablet. All the three superdisintegrant demonstrated great compressibility, great similarity, flowability and strength. Plan C3 of Ac-Di-sol superdisintegrant required least breaking down time, wetting time Compared to Formulations of Crosspovidone, or Sodium-starch glycoate with same fixation. Plan of Ac-Di-sol superdisintegrant (C3) had most extreme Formulation of Ac-Di-sol superdisintegrant (C3) have greatest water assimilation proportion, medicate discharge than all other definition and $98.4 \%$ discharge in $10 \mathrm{~min}$. 
Rania $\mathbf{H}$ et al ${ }^{(31)}$ explore the $\mathrm{pH}$-subordinate dissolvability and disintegration of pitifully fundamental Biopharmaceutical Classification Systems (BCS) class II drugs, described by low solvency and high porousness, utilizing Carvedilol Phosphate, a frail base with a pKa estimation of 7.8, as a model medication. A progression of dissolvability and in vitro disintegration contemplates was completed utilizing media that reenact the gastric and intestinal liquids and cover the physiological pH scope of the Gl from 1.2 to 7.8. The impact of ionic quality, cushion limit, and support types of the disintegration media on the solvency and disintegration conduct of Carvedilol Phosphate was likewise researched. The investigation uncovered that Carvedilol Phosphate showed a regular powerless base $\mathrm{pH}$-subordinate solvency profile with a high dissolvability at low $\mathrm{pH}(545.1-2591.4 \mu \mathrm{g} / \mathrm{mL}$ inside the $\mathrm{pH}$ run 1.2- 5.0) and low solvency at high $\mathrm{pH}(5.8-51.9 \mu \mathrm{g} / \mathrm{mL}$ inside the $\mathrm{pH}$ extend 6.5- 7.8). The disintegration conduct of Carvedilol Phosphate was steady with the solvency results, where Carvedilol Phosphate discharge was finished (95.8- 98.2\% discharged inside $60 \mathrm{~min}$ ) in media reproducing the gastric liquid $(\mathrm{pH} 1.2-5.0)$ and generally low (15.9- 86.2\% discharged inside $240 \mathrm{~min}$ ) in media recreating the intestinal liquid $(\mathrm{pH}$ 6.5- 7.8). It was discovered that the cradle types of the disintegration media may impact the dissolvability and thus the level of Carvedilol Phosphate discharged by shaping Carvedilol Phosphate salts of shifting solubilities. Carvedilol Phosphate solvency and disintegration diminished with expanding ionic quality, while bringing down the support limit brought about an abatement in Carvedilol Phosphate dissolvability and disintegration rate.

Jaimin $\mathbf{J}$ et al $^{\left({ }^{(32)}\right.}$ assessed the potential for time deferred discharge medicate conveyance arrangement of Carvedilol Phosphate. Carvedilol Phosphate picked as model medication with an expect to discharge tranquilize at early morning event of illness can be kept away from. Coordinate pressure technique was utilized for planning of tablets. The plan tablets were assessed for different parameters like hardness, thickness, normal weight, sedate substance, \% combined medication discharge. The upgraded definition F2 was exposed to strength consider for multi month. In starter clumps 3 polymers were utilized in mixes, from the gotten assessment information of primer bunches polymers (PHPMC AS HG and EUDRAGIT S 100 ) were chosen for further factorial structure groups, from the assessment parameter information, it had been seen that the normal weight of the readied tablets were in the scope of from 78 to $82 \mathrm{mg}$. Tablets of all clumps agreed to the mass variety necessity of Indian Pharmacopeia and no group fluctuated over $5 \%$ of the normal weight demonstrating consistency in the arrangement of the tablet with negligible cluster to bunch variety. The medication content investigation demonstrate that there was exact dissemination of the medication in the tablets and well inside the scope of $95.95-102.39 \%$ of the aggregate sum of the medication included tablets. It was inferred that definition of Carvedilol Phosphate had potential application as hostile to hypertension for time postponed conveyance of medication following in oral organization.

Joshi $\mathbf{P}$ et al ${ }^{(33)}$ create Carvedilol Phosphate gliding microsphere for maintenance in the upper piece of the GIT to enhance the disintegration where the solvency of Carvedilol Phosphate is more in acidic medium. Drifting Microspheres were set up by emulsion dissolvable dissemination strategy utilizing ethylcellulose and eudragit RS 100 as polymer and $0.5 \% \mathrm{w} / \mathrm{v}$ polyvinyl liquor as outer medium. $3^{2}$ full factorial structure was utilized for advancing the medication: polymer ratio(X1) and ethylcellulose: eudragit RS $100(\mathrm{X} 2)$ proportion were chosen as autonomous factors, assessed for different parameters which were broke down utilizing ANOVA and surface reaction procedure. Clump F5 was chosen as advanced, as gives wanted zero request discharge profile and additionally $77.25 \%$ lightness and $80.66 \%$ entanglement proficiency, $82.9 \%$ yield and mean molecule size of $133.86 \mu \mathrm{m}$ and circular microsphere got affirmed by SEM think about. Medication and excipients are compactible to one another was affirmed by FTIR. 


\subsection{Summary of PSAR}

Table 3: Summary of PSAR

\begin{tabular}{|l|l|l|}
\hline Sr. No. & Patent Application number & Title of Patent \\
\hline & EP1501500 A2 & Carvedilol Phosphate formulations \\
\hline & WO2015198339 A1 & Extended release compositions of Carvedilol Phosphate \\
\hline & US20040186158 A1 & Novel composition of Carvedilol Phosphate \\
\hline $21 / 2014$ & $\begin{array}{l}\text { An Improved Controlled Porosity Osmotic Pump of Trimetazidine } \\
\text { Dihydrochloride Tablet }\end{array}$ \\
\hline & $31 / 2007$ & Osmotic Dosage Forms for Controlled Delivery of Alprazolam \\
\hline
\end{tabular}

- Looking at above 05 patents, your Dissertation project is novel up to what extent? Novelty grade: 50 to $90 \%$

\section{- RATIONAL OF PATENT}

Above five patents describes Formulation of Carvedilol Phosphate in different dosage form. No any patented work done on Carvedilol Phosphate Osmotic drug delivery system. The principle of Osmotic drug delivery system preparation offers a simple and practical approach to achieve once a day dosing a therapeutically effective average steady-state plasma concentration of drug. Hence, the selected title is novel.

\section{AIM \& OBJECTIVES}

\subsection{Aim of Work}

"Formulation and Evaluation of Controlled Release Osmotic Tablet of Carvedilol Phosphate"

\subsection{Rationale}

$\checkmark$ Carvedilol Phosphate is a nonselective 6 -adrenergic blocking agent with $\alpha 1$-blocking activity.

$\checkmark \quad$ It is safe and effective in the treatment of hypertension, left ventricular dysfunction and heart failure.

$\checkmark$ Carvedilol Phosphate is quickly and extensively absorbed via oral administration with an absolute bioavailability $\mathbf{2 5 \%}$ - $35 \%$ due to a significant degree of first-pass metabolism.

$\checkmark$ Carvedilol Phosphate has a short half-life of 7 hours.

$\checkmark \quad$ Long-term therapy in hypertension by Carvedilol Phosphate may result in poor patient compliance since it has low bioavailability and short half-life, leading to increased frequency of administration.

$\checkmark$ Controlled release Carvedilol Phosphate formulation is therefore necessary for improving patient compliance and reducing frequency of administration.

$\checkmark$ The release of Carvedilol Phosphate can be extended and controlled by making it in Osmotic tablet, which are a class of novel drug delivery systems because of their so many advantages such as less frequent administration to produce the desired constant plasma concentration associated with improved patient compliance and controled drug delivery.

$\checkmark$ Hence, the present study was intended towards the development of controled/controlled release formulations of Carvedilol Phosphate based on osmotic technology. In this study, osmotic drug delivery systems for Carvedilol Phosphate were developed.

\subsection{Objectives of Work}

$\checkmark$ To carry out Drug: Excipient Compatibility study.

$\checkmark$ To formulate osmotic tablets of Carvedilol Phosphate.

$\checkmark$ To optimize the polymer concentration to achieve targeted drug release.

$\checkmark$ To achieve more than $90 \%$ drug release after 24 hours.

$\checkmark$ To optimize polymer coating.

$\checkmark \quad$ To evaluate various pre and post compression parameters. 
To carry out accelerated stability studies on the most satisfactory formulation as per ICH guideline.

4. MATERIALS AND EQUIPMENTS

4.1 List of Materials

Table 4: List of materials

\begin{tabular}{|l|l|l|l|}
\hline Sr. No. & Material & Function & Sources of Material \\
\hline 1. & Carvedilol Phosphate & API & Alembic Research Centre, Vadodara. \\
\hline 2. & $\begin{array}{l}\text { Microcrystalline Cellulose, } \\
\text { Pregelatinized Starch }\end{array}$ & Diluent & Balaji Chemicals, Ahmedabad. \\
\hline 3. & $\begin{array}{l}\text { Mannitol, } \\
\text { Sodium Chloride }\end{array}$ & Osmotic agent & S.D Fine Chemicals, Ahmedabad. \\
\hline 4 & Cellulose Acetate & Coating polymer & S.D Fine Chemicals, Ahmedabad. \\
\hline 5 & Low-substituted HPC & Binder & Balaji Chemicals, Ahmedabad. \\
\hline 6 & PEG 400 & Plasticizer & Balaji Chemicals, Ahmedabad. \\
\hline 7 & Povidone K30 & Pore-Former & Balaji Chemicals, Ahmedabad. \\
\hline 8 & Magnesium stearate & Lubricant & Balaji Chemicals, Ahmedabad. \\
\hline 9 & Talc & Glidant & Balaji Chemicals, Ahmedabad. \\
\hline
\end{tabular}

\subsection{List of Equipments}

Table 5 List of equipments

\begin{tabular}{|c|c|c|}
\hline Sr. No. & Equipments & Manufacturers \\
\hline 1. & Digital weighing balance & $\begin{array}{l}\text { Reptech weighing balance Itd., } \\
\text { Ahmadabad }\end{array}$ \\
\hline 2. & Tablet compression machine & $\begin{array}{l}\text { Multipunch Tablet compression machine, Cadmach } \\
\text { machinery Co. Pvt. Ltd, Ahmedabad. }\end{array}$ \\
\hline 3. & Dissolution apparatus & Electro lab Itd, Mumbai \\
\hline 4. & $\begin{array}{l}\text { U.V.Visible } \\
\text { spectrophotometer }\end{array}$ & Shimadzu-1601, Kroyoto, Japan. \\
\hline 5. & $\mathrm{pH}$ meter & Systronic, 361-micro pH meter. \\
\hline 6. & Roche Friabilator & Camp-bell Electronics, Mumbai, India \\
\hline 7. & Hardness Tester & $\begin{array}{l}\text { Validated dial type, Model:1101, Shivani Scientific } \\
\text { Industries Pvt. Ltd., Mumbai. }\end{array}$ \\
\hline 8. & Infrared spectrophotometer & Bruker, USA \\
\hline 9. & Differential scanning calorimeter & DSC TA-60, M/s Shimadzu \\
\hline 10. & Tablet Coating Machine & Solace Ltd. \\
\hline
\end{tabular}

\section{EXPERIMENTAL WORK}

\subsection{Preformulation Study}

\section{- Standardization of Drug:}

It essentially means confirmation of its identity and determination of its quality and purity which will be carried out under Preformulation study of drug. 


\subsubsection{Melting Point Determination:}

Melting point of the drug gives identity and purity of the drug. Any admixture will shift the melting point of the drug. It was determined by capillary method.

\subsubsection{Identification of Pure Drug:}

Identification of drugs was carried out by DSC/FT-IR.

\subsubsection{Physical Characterization of Active Ingredient:}

\section{a) Angle of repose ${ }^{36,37}$}

The angle of repose $(\theta)$ was estimated using fixed funnel method. The height of the funnel was adjusted in such a way that the tip of the funnel just touched the tip of the heap of the material. The material was allowed to flow through the funnel freely onto the surface. The diameter of the cone was measured and angle of repose was calculated using the following equation.

$\theta=\tan -1(h / r)$

where $h$ is the height and $r$ is the radius of the cone

Table 6: Angle of Repose Table

\begin{tabular}{|l|l|}
\hline Flow property & Angle of Repose (degrees) \\
\hline Excellent & $25-30$ \\
\hline Good & $31-35$ \\
\hline Fair - aid not needed & $36-40$ \\
\hline Passable - may hung up & $41-45$ \\
\hline Poor - must agitate, vibrate & $46-55$ \\
\hline Very poor & $56-65$ \\
\hline Very very poor & $>66$ \\
\hline
\end{tabular}

b) Bulk density ${ }^{36,37}$

Bulk density was determined by pouring a weighed quantity of material into a graduated cylinder and measuring the volume of the material. Bulk density was calculated using the following equation.

Bulk density $=m / v$

where $\mathrm{m}$ is weight of powder $(\mathrm{g}), \mathrm{v}$ is bulk volume $(\mathrm{ml})$

c) Tapped Density: ${ }^{36,37}$

Tapped density is the ratio of the mass of the material to the tapped volume of material. Tablet blend was poured into graduated cylinder. Then, the cylinder was allowed to 100 taps under its own weight onto a hard surface. Tapped density was calculated using following equation.

Tapped density $=m / v$

Where $\mathrm{m}$ is weight of powder $(\mathrm{g}), \mathrm{v}$ is Tapped Volume $(\mathrm{ml})$

d) Hausner's ratio: ${ }^{36,37}$

Hausner's ratio indicates the flow properties of the powder and measured by the ratio of tapped density to bulk density. Hausner's ratio was determined by the given formula 


\section{Hausner's Ratio $=$ Tapped density $/$ bulk density}

Table 7: Hausner's Ratio Table

\begin{tabular}{|l|l|}
\hline Flow property & Hausner's Ratio \\
\hline Excellent & $1.00-1.11$ \\
\hline Good & $1.12-1.18$ \\
\hline Fair - aid not needed & $1.19-1.25$ \\
\hline Passable - may hung up & $1.26-1.34$ \\
\hline Poor - must agitate, vibrate & $1.35-1.45$ \\
\hline Very poor & $1.46-1.59$ \\
\hline Very very poor & $>1.60$ \\
\hline
\end{tabular}

e) Carr's compressibility index: ${ }^{36,37}$

Compressibility is the ability of the powder to decrease in volume under pressure using bulk density and tapped density. It is indirectly related to the relative flow rate. Carr's compressibility index was determined by the following formula

\section{Carr's Index $(\%)=(1-$ Bulk density/Tapped density $)$ x100}

Table 8: Compressibility Index Table

\begin{tabular}{|l|l|}
\hline Flow property & Compressibility Index (\%) \\
\hline Excellent & $<10$ \\
\hline Good & $11-15$ \\
\hline Fair - aid not needed & $16-20$ \\
\hline Passable - may hung up & $21-25$ \\
\hline Poor - must agitate, vibrate & $26-31$ \\
\hline Very poor & $32-37$ \\
\hline Very very poor & $>38$ \\
\hline
\end{tabular}

\subsubsection{Solubility studies:}

Solubility plays an important part in the Preformulation study as it gives an idea about the BCS class of the drug and plays a pivotal role in the selection of dissolution media, which in turn helps in designing the formulation.

Solubility study was performed in Water and buffers with relevant physiological $\mathrm{pH}(1.2,4.5,6.8)$ at $37^{\circ} \mathrm{C}$.

Method:

An excess of the drug was added to $10 \mathrm{ml}$ of media in a small conical flask and was continuously shaken for 24 hours at $37^{\circ} \mathrm{C}$ in a conical flask shaker. After 24 hours, sample was filtered through Whatman filter paper no.1, diluted appropriately and the drug was estimated using a validated UV spectroscopy method.

\subsubsection{Analytical Method for Estimation of the Drug:}


In Preformulation studies it is very important to establish a simple UV-Visible Spectrophotometric analytical method to quantify the drug accurately in various tests.

\subsubsection{UV Absorption:}

Carvedilol Phosphate dissolved in selected solvents and further diluted suitably.

These solutions were scanned in the range 200 to $400 \mathrm{~nm}$ against respective blank to determine wavelength of absorption maxima or $\lambda$ max.

\subsubsection{Standard Calibration Curve:}

Drug $(100 \mathrm{mg}$ ) was taken and to this $40 \mathrm{ml}$ of methanol was added and shaken for about $20 \mathrm{~min}$ on mechanical shaker to obtain a clear solution. To this $0.1 \mathrm{~N} \mathrm{HCl}$ was added to make up the volume up to 100 $\mathrm{ml}$. From above solution various dilutions were prepared to get concentrations of 5, 10, 15, 20 and 30 $\mathrm{mcg} / \mathrm{ml}$. The absorbance of the various solutions was measured against methanolic $\mathrm{HCL}$ as a blank at $238 \mathrm{~nm}$ using double beam UV visible spectrophotometer. The graph of absorbance $\mathrm{v} / \mathrm{s}$ concentration was plotted and data were subjected to linear regression analysis in Microsoft excel.

\subsubsection{DRUG-EXCIPIENT COMPATIBILITY}

Drug-Excipient compatibility was performed in order to assess the suitability of excipients being used in the formulation. Some excipients tend to cause degradation of the drug thereby rendering impurity generation in the product, leading to compromise in patient safety. Hence this study is an integral part of preformulation studies and performed using FT-IR study.

\subsubsection{FT-IR STUDIES}

Compatibility of the drug with the Excipients is determined by comparing the spectra of drug with the physical mixture of the drug and the polymers.

\section{Method:}

The drug and drug-polymer mixture (1:1) were mixed with dried potassium bromide and compressed under 10-ton pressure for $5 \mathrm{~min}$ in a hydraulic press to form a transparent pellet. These pellets were scanned in the region of 4000 to $400 \mathrm{~cm}$-1using a Shimadzu FTIR 1700 Spectrophotometer.

\subsection{Dose Calculation}

\subsubsection{Dose Calculation for Carvedilol Phosphate for Controlled release Dosage form:-}

For controlled release dosage form, Dose calculation for $24 \mathrm{hrs}$ is calculated by below

equation;

$\mathrm{DT}=\mathrm{DL}(1+0.693 \times \mathrm{t} / \mathrm{t} 1 / 2)$

Where,

DT = Total Dose,

$\mathrm{DL}=$ Loading Dose $-12.5 \mathrm{mg}$ of Carvedilol Phosphate

$\mathrm{t}=$ Time require for drug release $-24 \mathrm{hrs}$,

$\mathrm{t} 1 / 2=$ half life of drug: $7 \mathrm{hrs}$

DT $=12.5(1+0.693 \times 24 / 7)=42.2 \mathrm{mg}$ of Carvedilol Phosphate.

Molecular weight of Carvedilol Phosphate $-406.482 \mathrm{~g} / \mathrm{mol}$

Molecular weight of Carvedilol Phosphate $-522.491 \mathrm{~g} / \mathrm{mol}$

So for $42.2 \mathrm{mg}$ of Carvedilol Phosphate, 
Amount of Carvedilol Phosphate $=(42.2 * 522.491) / 406.482$

$=\mathbf{5 4 . 2 4} \mathrm{mg} / \mathrm{tab}$ of Carvedilol Phosphate

\subsection{Formulation Development}

\section{By Direct Compression Method:}

Direct Compression Method was adopted as it is the simplest of approach for tablet fabrication. It involves least number of unit operations and is cost effective when it comes to commercialization of the product. Detailed formulae mentioned in table below.

Table 9: Formulation Optimization Table

\begin{tabular}{|c|c|c|c|c|c|c|c|c|c|c|c|c|}
\hline \multirow[b]{2}{*}{ Sr. No. } & \multirow[b]{2}{*}{ Ingredients } & \multicolumn{3}{|c|}{$\begin{array}{l}\text { Optimization of } \\
\text { Mannitol }\end{array}$} & \multicolumn{3}{|c|}{$\begin{array}{l}\text { Optimization of } \\
\text { Sodium chloride }\end{array}$} & \multicolumn{3}{|c|}{$\begin{array}{l}\text { Optimization of } \\
\text { Povidone K30 }\end{array}$} & \multicolumn{2}{|c|}{$\begin{array}{l}\text { Optimization } \\
\text { of coating wt } \\
\text { gain }\end{array}$} \\
\hline & & F1 & F2 & F3 & F4 & F5 & F6 & F7 & F8 & F9 & F10 & F11 \\
\hline & Core & \multicolumn{11}{|c|}{$\mathrm{Mg} / \mathrm{tab}$} \\
\hline 1 & Carvedilol Phosphate & 54.24 & 54.24 & 54.24 & 54.24 & 54.24 & 54.24 & 54.24 & 54.24 & 54.24 & 54.24 & 54.24 \\
\hline 2 & Microcrystalline Cellulose & 64.76 & 39.76 & 14.76 & 29.76 & 19.76 & 9.76 & 32.26 & 31.01 & 28.51 & 20.45 & 12.38 \\
\hline 3 & Pregelatinized Starch & 20.00 & 20.00 & 20.00 & 20.00 & 20.00 & 20.00 & 20.00 & 20.00 & 20.00 & 20.00 & 20.00 \\
\hline 4 & Low-substituted HPC & 15.00 & 15.00 & 15.00 & 15.00 & 15.00 & 15.00 & 15.00 & 15.00 & 15.00 & 15.00 & 15.00 \\
\hline 5 & Sodium Chloride & - & $\left.\right|^{-}$ & F & 10.00 & 20.00 & 30.00 & 10.00 & 10.00 & 10.00 & 10.00 & 10.00 \\
\hline 6 & Mannitol & 50.00 & 75.00 & 100.00 & 75.00 & 75.00 & 75.00 & 75.00 & 75.00 & 75.00 & 75.00 & 75.00 \\
\hline 7 & Talc & 5.00 & 5.00 & 5.00 & 5.00 & 5.00 & 5.00 & 5.00 & 5.00 & 5.00 & 5.00 & 5.00 \\
\hline \multirow[t]{2}{*}{8} & Magnesium Stearate & 10.00 & 10.00 & 10.00 & 10.00 & 10.00 & 10.00 & 10.00 & 10.00 & 10.00 & 10.00 & 10.00 \\
\hline & Coat & \multicolumn{11}{|c|}{$\mathrm{Mg} / \mathrm{tab}$} \\
\hline 1 & Cellulose Acetate 398-10 & 25.00 & 25.00 & 25.00 & 25.00 & 25.00 & 25.00 & 25.00 & 25.00 & 25.00 & 31.25 & 37.50 \\
\hline 2 & PEG 400 & 3.50 & 3.50 & 3.50 & 3.50 & 3.50 & 3.50 & 3.50 & 3.50 & 3.50 & 4.38 & 5.25 \\
\hline \multirow[t]{2}{*}{3} & Povidone K30 & 2.50 & 2.50 & 2.50 & 2.50 & 2.50 & 2.50 & - & 1.25 & 3.75 & 4.69 & 5.63 \\
\hline & Total & 250.00 & 250.00 & 250.00 & 250.00 & 250.0 & 0250.00 & 250.00 & 0250.00 & 0250.00 & 0250.00 & 0250.00 \\
\hline
\end{tabular}




\section{Procedure:}

1. Dispensing and Sifting

a) Dispensed quantity of Carvedilol Phosphate, Microcrystalline Cellulose, Pregelatinized Starch, Low-substituted HPC, Sodium, Chloride and Mannitol were sifted through \#40 mesh.

b) Talc and Magnesium Stearate were sifted through \#60 mesh.

2. Blending and Lubrication:

a) Material of Step 1 was transferred to a Double Cone blender and the material was blended together for 15 minutes at 20 RPM.

b) To the above blended material, sifted Talc and Magnesium Stearate were added and the blend was lubricated for 5 minutes at 20 RPM.

The blend was then evaluated for pre-compaction parameters

\section{Compression:}

The blend from step 2.b was compressed using Multipunch Tablet compression machine from Cadmach machinery using $10 \mathrm{~mm}$ round shaped punches.

\section{Coating:}

a) Coating Solution Preparation:

Cellulose acetate, PEG 400 and Povidone K30 were dissolved in 8:2 solvent mixture of Acetone and Ethanol by allowing cellulose acetate to hydrate for 2 hours and then stirring continuously for 2 hours.

\section{b) Coating Process:}

Tablets obtained from Step 3 were coated using a Tablet coater using solution from Step 4.a.

The tablets were then evaluated for post compression parameters of Osmotic Controlled Release Tablet.

\section{Post Compression Parameters:}

1) Weight Variation: ${ }^{36,38,39}$

Weight variation was performed to ensure dosage uniformity. The test was carried out by weighing the 20 tablets individually using analytical balance, then calculating the average weight, and comparing the individual tablet weights to the average. The percentage of weight variation was calculated by using the following formula.

Table 10: Weight Variation

\begin{tabular}{|l|l|l|}
\hline Sr. No. & Average Weight of tablets $(\mathbf{m g})$ & Maximum \% difference allowed \\
\hline 1 & $<130$ & $\pm 10 \%$ \\
\hline 2 & $130-324$ & $\pm 7.5 \%$ \\
\hline 3 & $>324$ & $\pm 5 \%$ \\
\hline
\end{tabular}

2) Thickness: ${ }^{38,39}$

Thickness will affect the physical appearance of the tablet and will be governed by the compressibility of the blend and the target hardness. It is measured in $\mathrm{mm}$.

3) Hardness: ${ }^{38,39}$

Hardness is also so called crushing strength. It is the load required to crush the tablet when placed on its edge. Tablets must be able to withstand the rigors of handling and transportation experienced in the manufacturing plant, in the drug distribution system, and in the field at the hands of the end users (patients/consumers). For these reasons, the mechanical strength of tablets is of considerable importance and is routinely measured. It is measured in Newton or $\mathrm{kg} / \mathrm{cm}^{2}$ or kilo Newton.

4) Friability (core tablets): ${ }^{38,39}$ 
Friability is defined as the \%weight loss by tablets due to mechanical action during the test. It refers to the ability of the compressed tablet to avoid fracture and breaking during transport.

Friability of a tablet is calculated by below mentioned formula:

\%friability $=$ (1-Final weight/Initial weight $) * 100$

\section{5) Dissolution:}

The release rate of Carvedilol Phosphate from controlled release tablet was determined using United State Pharmacopoeia (USP) XXIV dissolution testing apparatus II (paddle method). The dissolution test was performed using $900 \mathrm{ml}$ of $0.1 \mathrm{~N} \mathrm{HCl} \mathrm{pH} 1.2$ followed by $\mathrm{pH} 6.8$ phosphate buffer as dissolution medium, at $37 \pm 0.5^{\circ} \mathrm{C}$ and $50 \mathrm{rpm}$. A sample $(5 \mathrm{ml})$ of the solution was withdrawn from the dissolution apparatus at $1,2,3,4,6,8,12,16,20$ and 24 hours. The samples were filtered through a 0.45 membrane filter. Absorbance of these solutions was measured at $238 \mathrm{~nm}$ using a Shimadzu spectrophotometer. Cumulative percentage of drug release was calculated using an equation obtained from a standard curve.

\section{6) Drug Content:}

20 tablets were weighed and powdered. Blend equivalent to $100 \mathrm{mg}$ of Carvedilol Phosphate was weighed and transferred to $100 \mathrm{ml}$ volumetric flask. To it $50 \mathrm{ml}$ of $0.1 \mathrm{~N} \mathrm{HCl}$ was added and shaken until drug was completely dissolved. The solution was made up to $100 \mathrm{ml}$ with $0.1 \mathrm{~N} \mathrm{HCl}$ and suitably diluted to similar concentration as that of the standard to obtain sample solution.

\section{7) Stability study}

Carvedilol Phosphate OROS (optimized batch) were kept for one month and the stability of the tablets monitored up to 1 month at accelerated stability conditions ( $40 \circ \mathrm{C}$ temperature and $75 \pm 5 \%$ $\mathrm{RH})$. Samples will be removed and characterized by Appearance, Hardness, Friability, Disintegration Time, in-vitro drug release study and drug content.

\section{RESULTS AND DISCUSSION}

\subsection{Preformulation Study}

The results and conclusion of the Preformulation studies carried out on Active Ingredient are documented below

\subsubsection{MELTING POINT DETERMINATION:}

The melting point of the Active Ingredient was found to be $114^{\circ} \mathrm{C}$, which is found to be consistent with that of reported melting point of pure Carvedilol Phosphate. This confirms the purity of the material.

\subsubsection{IDENTIFICATION OF PURE DRUG:}

The identification of the pure drug was done by Differential Scanning Calorimetry. Pure Carvedilol Phosphate shows melting range of between $112^{\circ} \mathrm{C}-121^{\circ} \mathrm{C}$. DSC trace wherein the melting endotherm was found at $117.6^{\circ} \mathrm{C}$. 


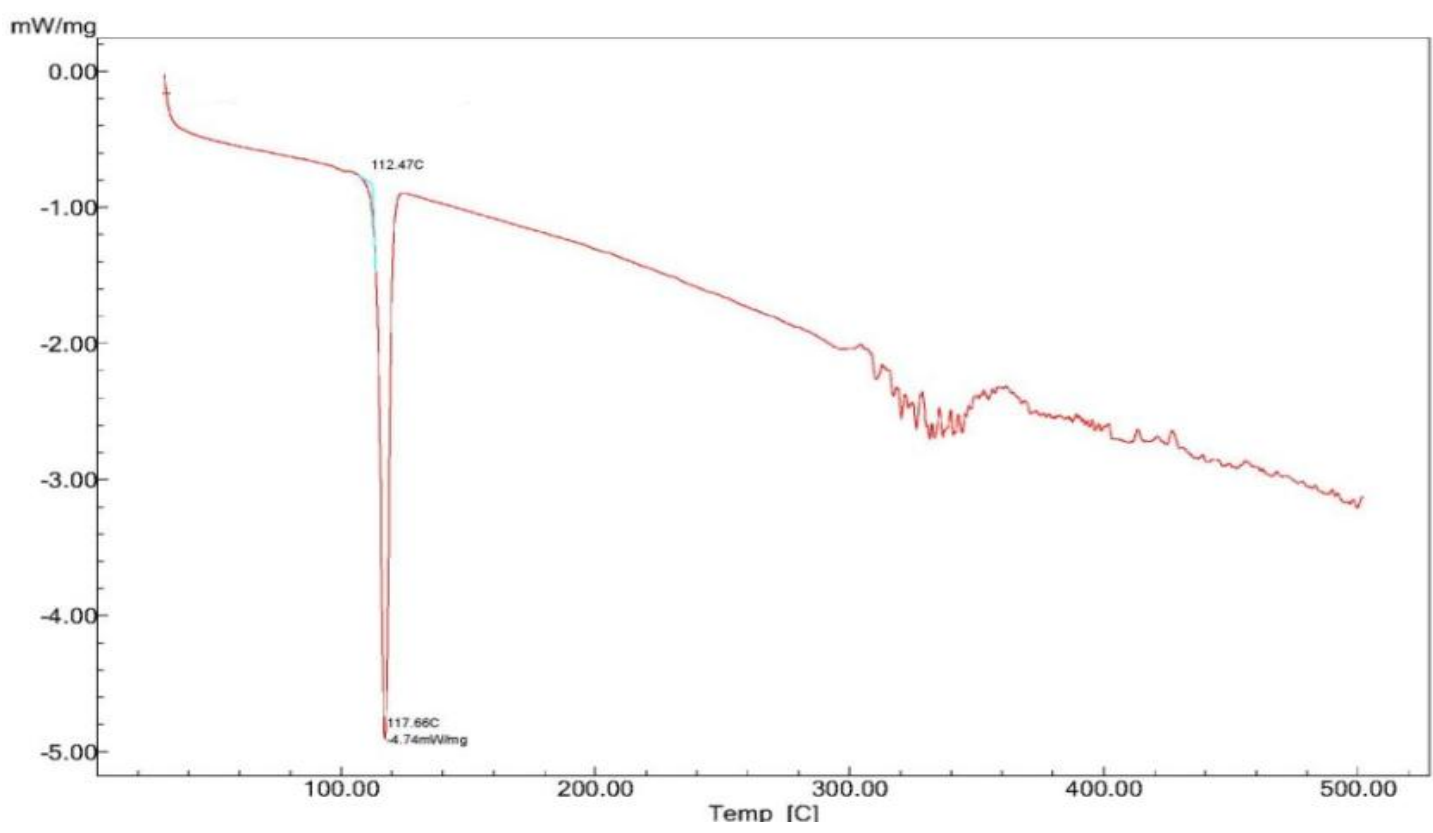

Figure 4: DSC Curve of Pure Carvedilol Phosphate

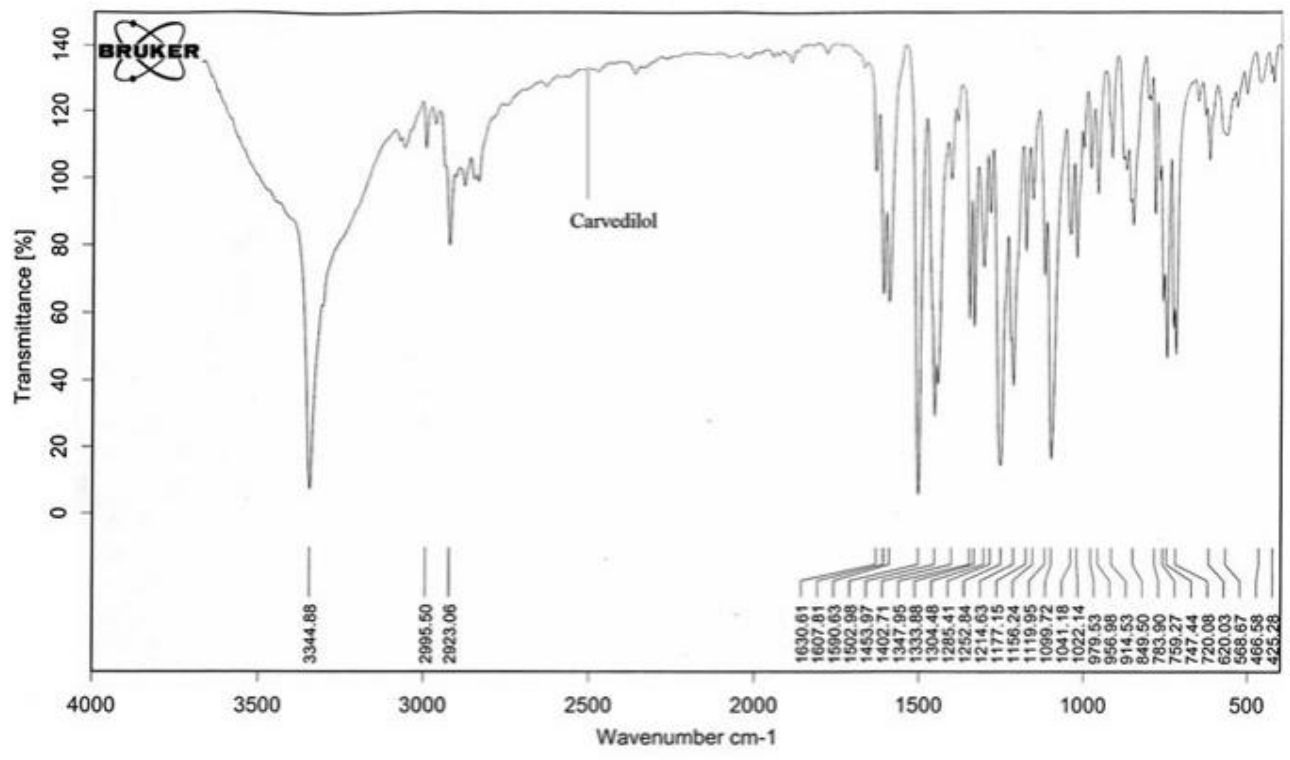

Figure 5: FT-IR of Pure Carvedilol Phosphate

\subsubsection{Physical Characterization of drug:}

Observations from the test results of physical characterization of the drug are tabulated below:

Table 11: Results of Physical Characterization of Carvedilol Phosphate

\begin{tabular}{|l|l|l|l|}
\hline Sr. No. & Test & Results & Inference \\
\hline 1 & Angle of Repose & 47.3 & Poor flow \\
\hline 2 & Bulk Density (g/cc) & 0.356 & \\
\hline 3 & Tapped Density (g/cc) & 0.501 & \\
\hline 4 & Hausner's Ratio & 1.407 & Poor flow \\
\hline 5 & Carr's Consolidation Index & 28.94 & Poor flow \\
\hline
\end{tabular}




\section{Conclusion:}

Carvedilol Phosphate has poor flow as shown by above mentioned tests. Hence proper selection of excipients and process is essential.

\subsubsection{Solubility Studies:}

Solubility of pure Carvedilol Phosphate was evaluated in different media and the results were recorded in the table below. Results are tabulated below:

Table 12: Solubility Studies Data

\begin{tabular}{|l|l|l|}
\hline Sr. No. & Media & Solubility $(\mathrm{mg} / \mathrm{ml})$ \\
\hline 1 & Purified Water & $0.057 \pm 0.04$ \\
\hline 2 & pH 1.2 HCl buffer & $2.591 \pm 0.03$ \\
\hline 3 & HH 4.5 acetate buffer & $0.545 \pm 0.05$ \\
\hline 4 & pH 6.8 phosphate buffer & $0.061 \pm 0.04$ \\
\hline
\end{tabular}

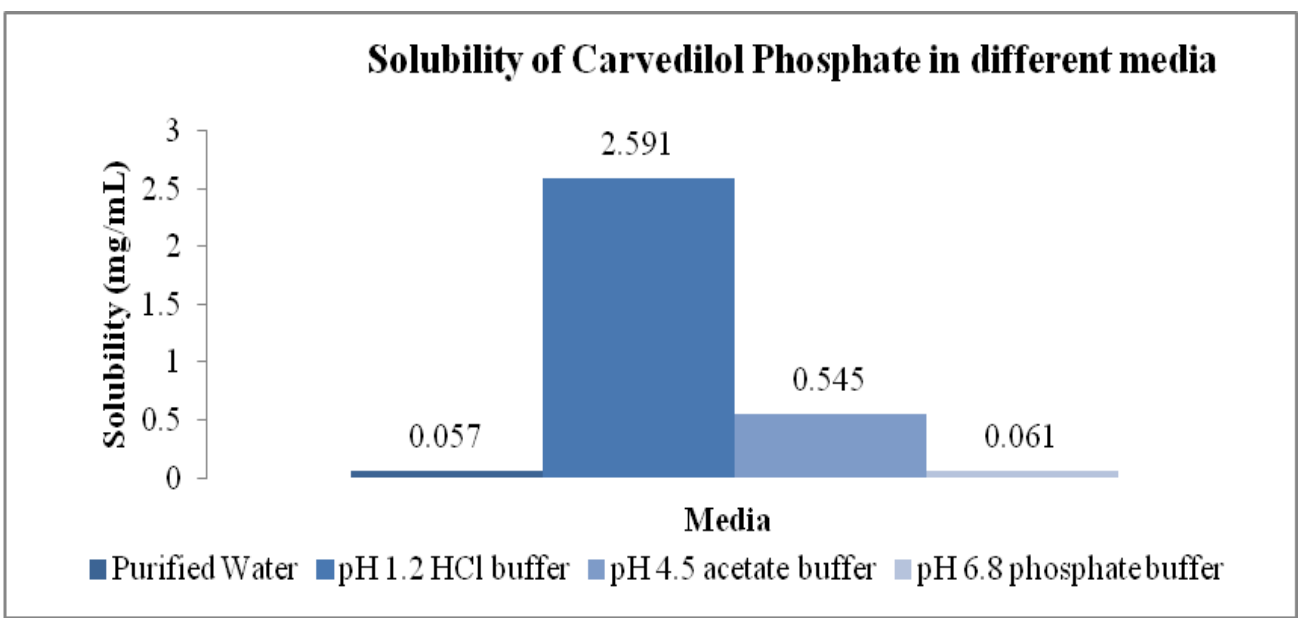

\subsubsection{ANALYTICAL METHOD FOR ESTIMATION}

\subsubsection{UV ABSORPTION}

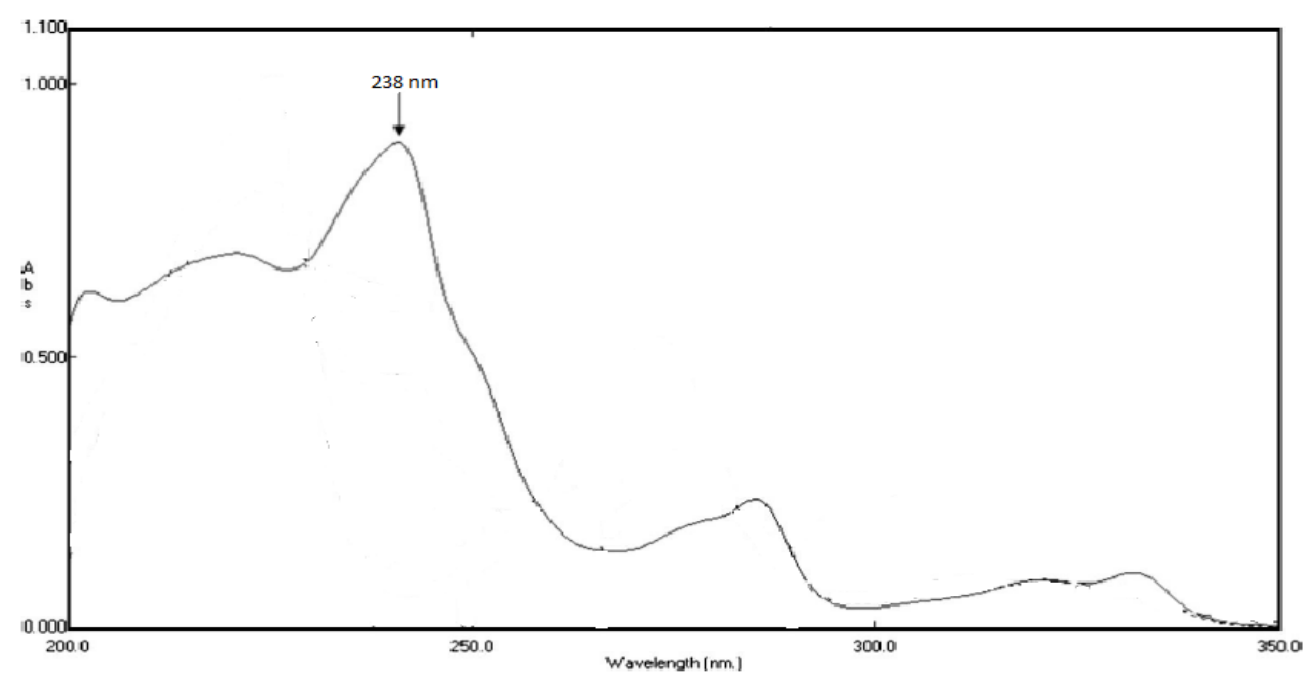

Figure 6: $\lambda \max$ of Pure Carvedilol Phosphate

Scanning the Carvedilol Phosphate stock solution showed that the $\lambda$ max of Carvedilol Phosphate was $238 \mathrm{~nm}$ and all further analysis will be done at this particular wavelength. 


\subsubsection{STANDARD CALIBRATION CURVE}

Table 13: Standard calibration curve of Carvedilol Phosphate in $0.1 \mathrm{~N} \mathrm{HCl}$

\begin{tabular}{|l|l|l|}
\hline Sr. No. & Concentration $(\boldsymbol{\mu g} / \mathrm{ml})$ & Avg. Abs \pm SD \\
\hline 1. & 5 & $0.158 \pm 0.014$ \\
\hline 2. & 10 & $0.325 \pm 0.028$ \\
\hline 3. & 15 & $0.499 \pm 0.048$ \\
\hline 4. & 20 & $0.640 \pm 0.033$ \\
\hline 5. & 25 & $0.817 \pm 0.068$ \\
\hline 6. & 30 & $0.990 \pm 0.092$ \\
\hline
\end{tabular}

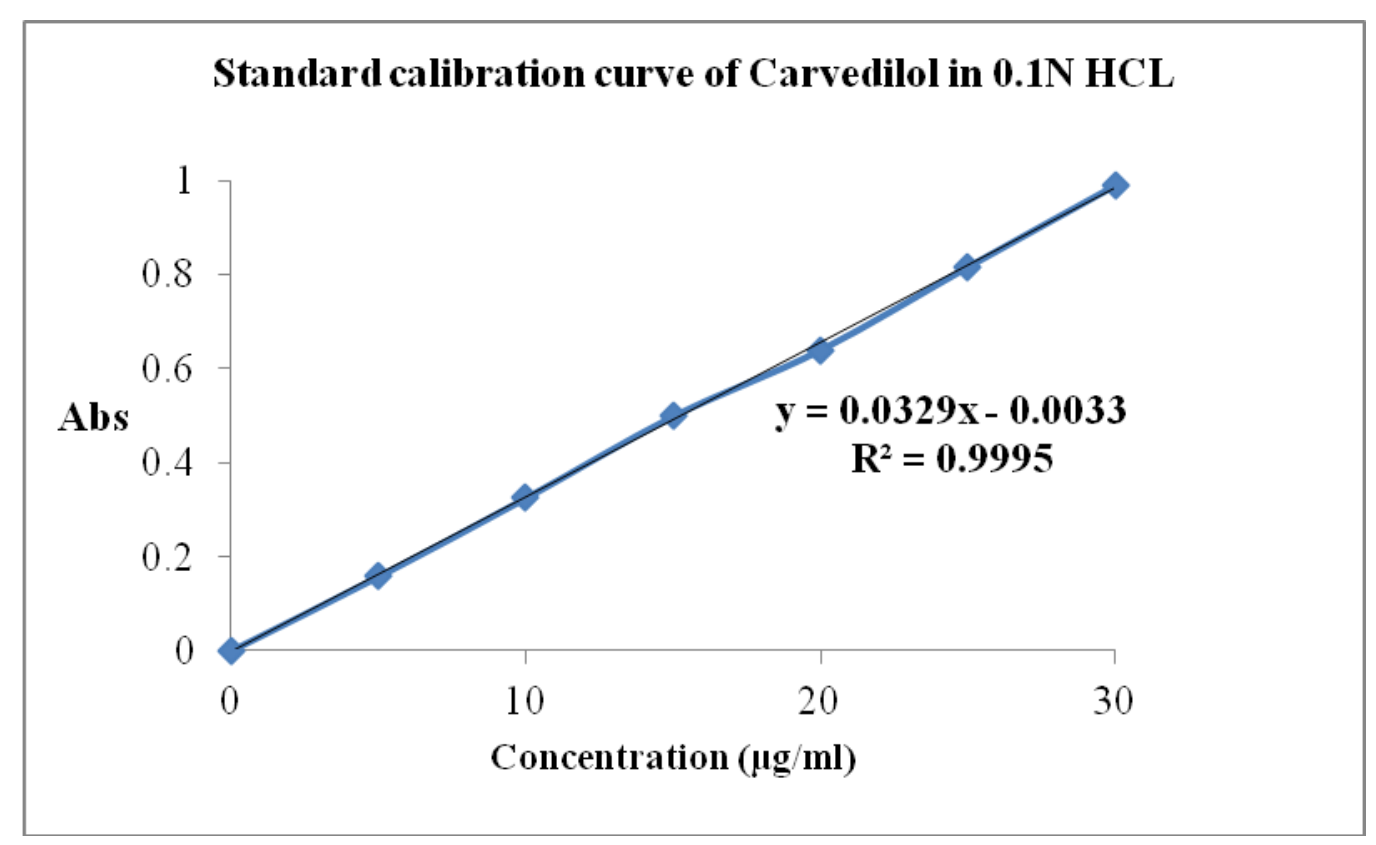

Figure 7: Standard calibration curve of Carvedilol Phosphate in $0.1 \mathrm{~N} \mathrm{HCl}$

Table 14 : Standard calibration curve of Carvedilol Phosphate in 6.8 phosphate buffer

\begin{tabular}{|l|l|l|}
\hline Sr. No. & Concentration $(\mu \mathrm{g} / \mathrm{ml})$ & Avg. Abs \pm SD \\
\hline 1. & 5 & $0.161 \pm 0.010$ \\
\hline 2. & 10 & $0.329 \pm 0.023$ \\
\hline 3. & 15 & $0.503 \pm 0.044$ \\
\hline 4. & 20 & $0.651 \pm 0.030$ \\
\hline 5. & 25 & $0.823 \pm 0.063$ \\
\hline 6. & 30 & $0.995 \pm 0.092$ \\
\hline
\end{tabular}




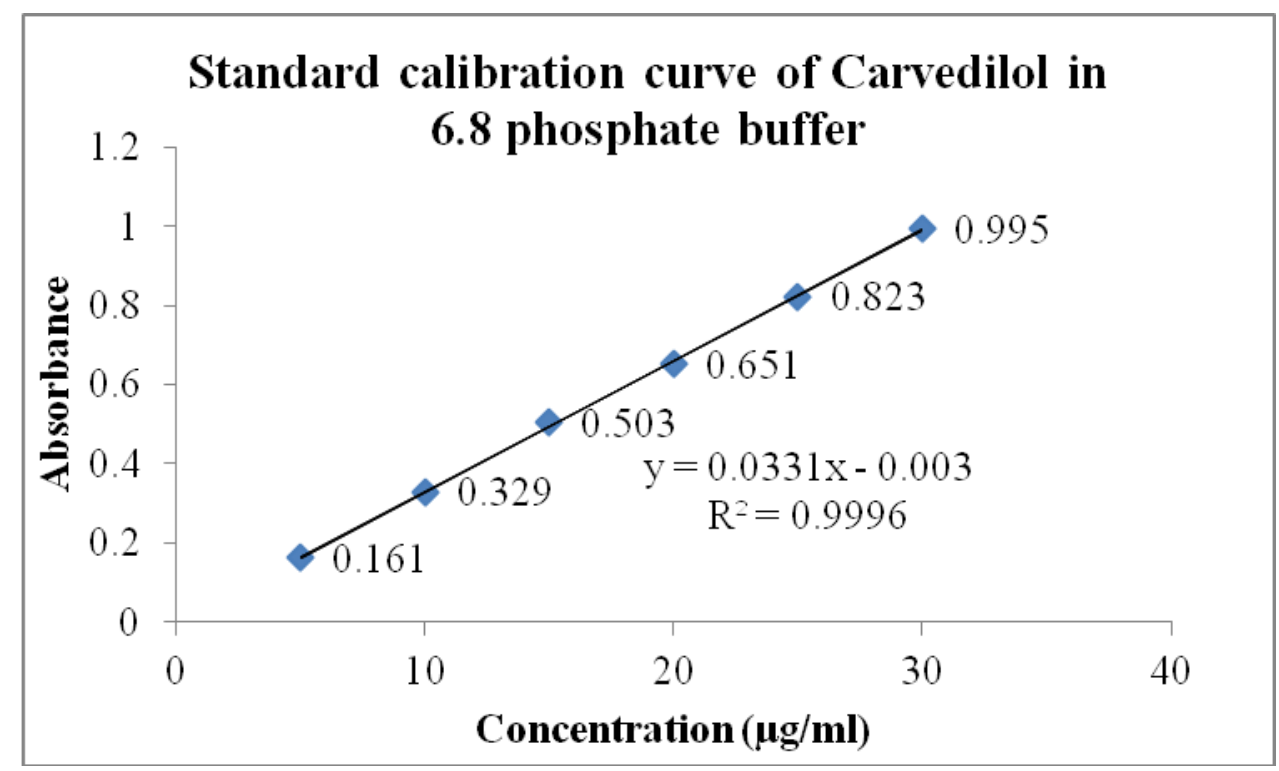

Figure 8: Calibration Curve in 6.8 phosphate buffer

\subsubsection{DRUG-EXCIPIENT COMPATIBILITY}

\subsubsection{FT-IR STUDIES}

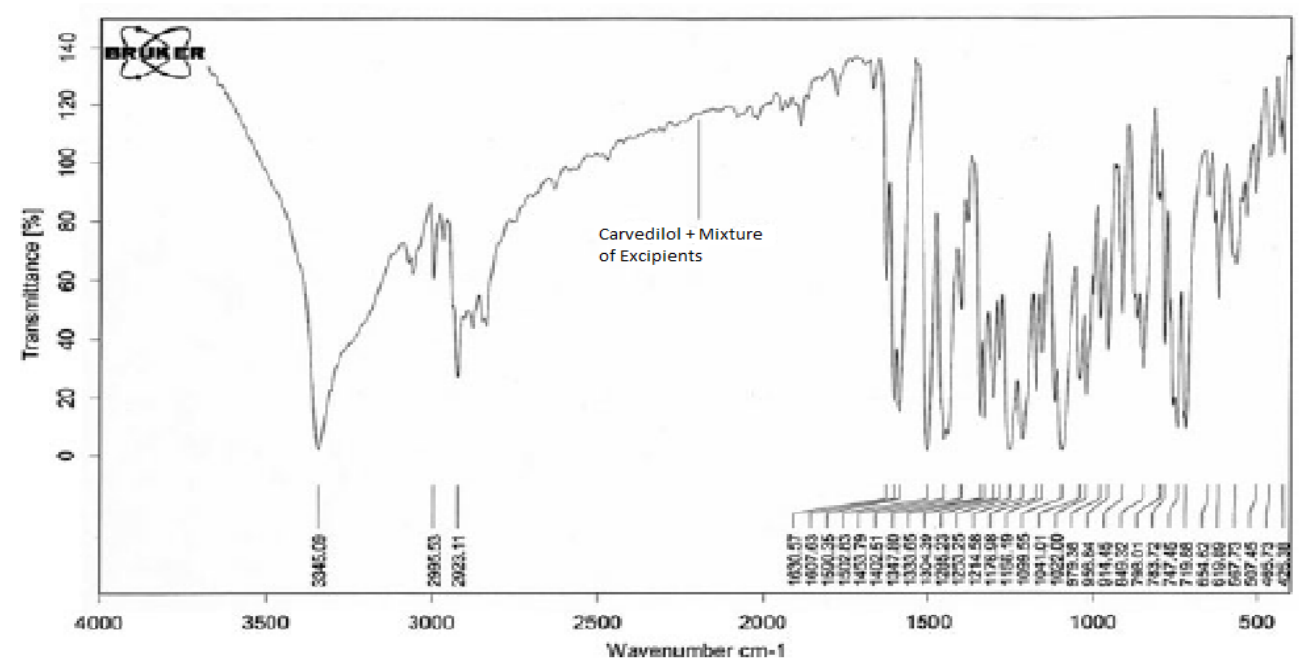

Figure 9: FT-IR of Carvedilol Phosphate + Excipients

The figure above shows that there is no change in the FTIR pattern of all the functional groups of Carvedilol Phosphate is present in the physical mixture of drug and excipients. Characteristic peaks like $-\mathrm{OH}\left(3600-3200 \mathrm{~cm}^{-1}\right),-\mathrm{CH}_{3}$

$\left(1465-1440 \mathrm{~cm}^{-1}\right)$ and $-\mathrm{NH}\left(3500-3300 \mathrm{~cm}^{-1}\right)$ are consistent in both FT-IR graphs. Hence, it can be concluded that the excipients selected are compatible with the drug and can be used for further evaluation.

\subsection{Evaluation of Formulation}

All the formulations (blend and tablets) were evaluated for pre-compression and post-compression parameters mentioned.

\subsubsection{PRE-COMPRESSION PARAMETERS}

Precompression parameters of all the blends (F1 to F11) and it was observed that there was no significant difference amongst all the blends in terms of flowability and compressibility. It could be 
possible because of the fact that the blends were prepared by diluents with very good flow property. All pre compression parameters are tabulated below

Table 15: Results of Pre-Compression Parameters of blend

\begin{tabular}{|l|l|l|l|l|l|}
\hline Formulations & $\begin{array}{l}\text { Angle of } \\
\text { Repose } \\
(\boldsymbol{\theta})\end{array}$ & $\begin{array}{l}\text { Bulk Density } \\
(\mathrm{g} / \mathrm{cc})\end{array}$ & $\begin{array}{l}\text { Tapped } \\
\text { Density }(\mathrm{g} / \mathrm{cc})\end{array}$ & $\begin{array}{l}\text { Carr's } \\
\text { Consolidation } \\
\text { Index }(\%)\end{array}$ & $\begin{array}{l}\text { Hausner's } \\
\text { Ratio }\end{array}$ \\
\hline F1 & $28.4 \pm 1.9$ & $0.3142 \pm 0.03$ & $0.4357 \pm 0.09$ & $27.886 \pm 0.90$ & $1.387 \pm 0.06$ \\
\hline F2 & $31.6 \pm 1.2$ & $0.3256 \pm 0.04$ & $0.4419 \pm 0.18$ & $26.318 \pm 1.20$ & $1.357 \pm 0.05$ \\
\hline F3 & $33.1 \pm 0.9$ & $0.3371 \pm 0.03$ & $0.4520 \pm 0.08$ & $25.420 \pm 1.29$ & $1.341 \pm 0.09$ \\
\hline F4 & $29.3 \pm 1.3$ & $0.3487 \pm 0.05$ & $0.4680 \pm 0.07$ & $25.491 \pm 1.21$ & $1.342 \pm 0.08$ \\
\hline F5 & $27.0 \pm 0.8$ & $0.3612 \pm 0.06$ & $0.4797 \pm 0.16$ & $24.703 \pm 1.22$ & $1.328 \pm 0.12$ \\
\hline F6 & $25.3 \pm 0.7$ & $0.3656 \pm 0.05$ & $0.4873 \pm 0.18$ & $24.974 \pm 0.95$ & $1.333 \pm 0.13$ \\
\hline F7 & $28.7 \pm 1.5$ & $0.3423 \pm 0.08$ & $0.4671 \pm 0.12$ & $26.718 \pm 0.93$ & $1.365 \pm 0.10$ \\
\hline F8 & $29.1 \pm 1.3$ & $0.3439 \pm 0.09$ & $0.471 \pm 00.22$ & $26.985 \pm 0.81$ & $1.370 \pm 0.13$ \\
\hline F9 & $28.6 \pm 1.5$ & $0.3477 \pm 0.08$ & $0.4672 \pm 0.08$ & $25.578 \pm 1.16$ & $1.344 \pm 0.08$ \\
\hline F10 & $28.9 \pm 0.8$ & $0.3500 \pm 0.07$ & $0.4728 \pm 0.09$ & $25.973 \pm 1.19$ & $1.351 \pm 0.08$ \\
\hline F11 & $27.2 \pm 0.7$ & $0.3488 \pm 0.06$ & $0.4690 \pm 0.07$ & $25.629 \pm 0.85$ & $1.345 \pm 0.05$ \\
\hline
\end{tabular}

6.2.2 POST COMPRESSION PARAMETERS:

\section{1) Weight Variation:}

Weight Variation of all the Formulations was found well within the prescribed Pharmacopoeial limits of NMT 5.0\%. A good flow could be attritubuted to diluent selection and granulation process which has substantial effect on powder flow.

\section{2) Thickness:}

All the formulations were compacted to achieve a target hardness of $15 \mathrm{~kg} / \mathrm{cm}^{2}$. All formulations showed little to no variation in thickness because of high polymer concentration in the formulation.

\section{3) Hardness:}

Target Hardness was optimized to $15 \mathrm{~kg} / \mathrm{cm}^{2}$ keeping in mind the tablet weight and dimensions. All formulations were easily compressible as it had sufficient binder and polymer quantity to be compacted. A high hardness was selected as the coating process would last long and a lower hardness could lead to chipping and core erosion during coating process.

\section{4) Friability:}

Friability for all the formulation was well below the Pharmacopoeial limit of NMT 1.0\%. Proper selection of hardness and a good compactibility of the blend resulted in a satisfactory friability result. Friability is an important Quality Attribute as a poor friability may lead to complication $s$ during coating process.

\section{5) Dissolution:}

The main aim of the study was to develop a formulation which would sustain the drug release for a period of 24 hours.

\section{Effect of Osmogen:}

From the release pattern it was found that Sodium Chloride is a much more potent osmogen when compared to Mannitol, which was supported by literature, claiming that Osmotic capacity of $\mathrm{NaCl}$ was 356 and of Mannitol was 38. So a mixture of both was optimized to obtain a zero order release. 
Since varying quantities of osmogens changes release rate of the drug, it can be concluded that osmosis is the driving force for drug release from the tablets.

\section{Effect of Pore forming agent:}

Povidone K30 was selected as pore-former for coating. As Povidone is soluble in water, it solubilizes itself on contact with water and forms channels through which solute can come out. It is evident from the dissolution results that increasing pore former concentration in the coating increases drug release rate from the tablet.

\section{Effect of \%weight gain of coating agent:}

The choice of polymer for osmotic tablet was Cellulose Acetate, which forms a semi-permeable membrane, i.e. it allows entry of water in the tablet but does not allow the solute to pass through it. So increasing the concentration of the polymer will increase the barrier for the solute to pass through the membrane, hence, retarding the rate of dissolution.

Based on all physicochemical attributes, formulation F4 was found to be the best optimized batch and can be studied further.

Table 16: Results of Post-Compression Parameters

\begin{tabular}{|ll|l|l|l|l|}
\hline Formulation & $\begin{array}{l}\text { Weight } \\
\text { Variation }(\%)\end{array}$ & $\begin{array}{l}\text { Thickness } \\
(\mathrm{mm})\end{array}$ & $\begin{array}{l}\text { Hardness } \\
\left(\mathrm{kg} / \mathrm{cm}^{2}\right)\end{array}$ & $\begin{array}{l}\text { Friability } \\
(\%)\end{array}$ & Assay (\%) \\
\hline F1 & $250.9 \pm 3.7$ & $4.56 \pm 0.05$ & $15.1 \pm 4.6$ & $0.030 \pm 0.03$ & $100.2 \pm 0.2$ \\
\hline F2 & $249.8 \pm 3.9$ & $4.62 \pm 0.09$ & $15.0 \pm 5.1$ & $0.037 \pm 004$ & $99.9 \pm 0.5$ \\
\hline F3 & $248.9 \pm 2.4$ & $4.67 \pm 0.07$ & $14.9 \pm 7.3$ & $0.027 \pm 0.03$ & $99.8 \pm 0.6$ \\
\hline F4 & $250.3 \pm 3.7$ & $4.62 \pm 0.06$ & $15.1 \pm 6.4$ & $0.023 \pm 0.02$ & $98.9 \pm 0.7$ \\
\hline F5 & $2509 \pm 4.1$ & $4.61 \pm 0.04$ & $15.0 \pm 7.4$ & $0.031 \pm 0.03$ & $98.6 \pm 0.1$ \\
\hline F6 & $251.4 \pm 3.1$ & $4.60 \pm 0.06$ & $14.8 \pm 6.1$ & $0.028 \pm 0.03$ & $101.2 \pm 0.3$ \\
\hline F7 & $250.9 \pm 2.9$ & $4.61 \pm 0.07$ & $14.9 \pm 5.5$ & $0.026 \pm 0.03$ & $99.7 \pm 0.5$ \\
\hline F8 & $252.1 \pm 2.6$ & $4.62 \pm 0.06$ & $15.3 \pm 5.0$ & $0.027 \pm 0.02$ & $99.9 \pm 0.8$ \\
\hline F9 & $251.6 \pm 2.4$ & $4.60 \pm 0.06$ & $15.0 \pm 4.9$ & $0.024 \pm 0.02$ & $100.1 \pm 0.9$ \\
\hline F10 & $250.3 \pm 2.3$ & $4.62 \pm 0.05$ & $15.0 \pm 4.6$ & $0.028 \pm 0.04$ & $100.2 \pm 0.8$ \\
\hline F11 & $251.3 \pm 2.5$ & $4.61 \pm 0.06$ & $14.9 \pm 4.5$ & $0.027 \pm 0.03$ & $99.3 \pm 1.0$ \\
\hline
\end{tabular}


Table 17: Results of Dissolution Studies

\begin{tabular}{|c|c|c|c|c|c|c|c|c|c|c|c|}
\hline \multirow{2}{*}{ Formulations } & \multicolumn{11}{|c|}{$\begin{array}{l}\text { \% Cumulative Drug Release in } 900 \mathrm{ml}, 0.1 \mathrm{~N} \mathrm{HCl} \text {, followed by pH } 6.8 \text { phosphate } \\
\text { buffer after } 2 \text { hours at } 50 \text { RPM Paddle }\end{array}$} \\
\hline & & $\begin{array}{l}1 \\
\text { hour }\end{array}$ & $\begin{array}{l}2 \\
\text { hours }\end{array}$ & $\begin{array}{l}3 \\
\text { hours }\end{array}$ & $\begin{array}{l} \\
\text { hours }\end{array}$ & $\begin{array}{l}6 \\
\text { hours }\end{array}$ & 8 & $\begin{array}{l}12 \\
\text { hours }\end{array}$ & $\begin{array}{l}16 \\
\text { hours }\end{array}$ & $\begin{array}{l}20 \\
\text { hours }\end{array}$ & $\begin{array}{l}24 \\
\text { hours }\end{array}$ \\
\hline \multirow{2}{*}{ F1 } & $\%$ CDR & 1.5 & 3.9 & 6.2 & 9.2 & 13.4 & 19.4 & 27.3 & 37.4 & 48.2 & 58.8 \\
\hline & $\%$ RSD & 7.6 & 5.4 & 4.7 & 3.1 & 2.2 & 2.5 & 2.1 & 1.9 & 1.4 & 1.3 \\
\hline \multirow{2}{*}{ F2 } & $\%$ CDR & 2.3 & 4.5 & 8.4 & 12.4 & 16.3 & 22.4 & 32.1 & 44.3 & 53.6 & 65.3 \\
\hline & $\%$ RSD & 8.4 & 6.1 & 5.3 & 3.6 & 2.8 & 2.6 & 2.5 & 1.7 & 1.6 & 1.5 \\
\hline \multirow{2}{*}{ F3 } & $\%$ CDR & 3.1 & 5.2 & 9.3 & 14.0 & 20.1 & 27.4 & 39.4 & 52.1 & 65.3 & 78.4 \\
\hline & $\%$ RSD & 7.3 & 6.4 & 5.2 & 4.7 & 4.2 & 4.1 & 3.4 & 3.0 & 2.9 & 1.5 \\
\hline \multirow{2}{*}{ F4 } & $\%$ CDR & 5.4 & 9.7 & 14.9 & 19.4 & 27.3 & 35.4 & 51.6 & 66.7 & 84.2 & 100.3 \\
\hline & $\% \mathrm{RSD}$ & 8.0 & 6.6 & 5.1 & 4.3 & 4.0 & 3.7 & 3.1 & 2.6 & 2.4 & 1.7 \\
\hline \multirow{2}{*}{ F5 } & $\%$ CDR & 13.0 & 23.9 & 33.1 & 42.7 & 55.4 & 66.6 & 84.1 & 98.3 & 99.7 & 99.9 \\
\hline & $\%$ RSD & 7.1 & 6.4 & 5.2 & 4.9 & 4.1 & 3.7 & 3.2 & 2.7 & 2.2 & 1.6 \\
\hline \multirow{2}{*}{ F6 } & $\%$ CDR & 21.4 & 39.7 & 52.7 & 65.4 & 81.6 & 92.7 & 99.4 & 99.5 & 99.4 & 99.6 \\
\hline & $\%$ RSD & 7.4 & 6.2 & 5.3 & 4.7 & 3.7 & 3.1 & 2.9 & 2.4 & 2.1 & 1.3 \\
\hline \multirow{2}{*}{ F7 } & $\%$ CDR & 0.5 & 2.7 & 4.3 & 8.1 & 12.4 & 19.6 & 25.3 & 33.8 & 38 & 44.2 \\
\hline & $\%$ RSD & 9.9 & 7.6 & 5.4 & 4.1 & 3.9 & 3.7 & 3.4 & 2.7 & 2.4 & 2.0 \\
\hline \multirow{2}{*}{ F8 } & $\%$ CDR & 2.9 & 4.8 & 9.7 & 15.3 & 22.1 & 28.6 & 39.7 & 51.3 & 63.7 & 74.8 \\
\hline & $\%$ RSD & 7.6 & 6.4 & 5.9 & 4.5 & 4.3 & 3.8 & 3.1 & 2.6 & 2.1 & 1.3 \\
\hline \multirow{2}{*}{ F9 } & $\%$ CDR & 6.7 & 12.6 & 18.6 & 24.6 & 37.4 & 51.4 & 75.9 & 99.6 & 100.1 & 99.9 \\
\hline & $\%$ RSD & 8.8 & 7.1 & 6.4 & 5.3 & 4.9 & 3.4 & 2.9 & 1.4 & 1.2 & 1.2 \\
\hline \multirow{2}{*}{ F10 } & $\%$ CDR & 4.6 & 7.4 & 11.3 & 18.4 & 23.1 & 34.7 & 48.7 & 64.3 & 80.9 & 94.6 \\
\hline & $\%$ RSD & 7.3 & 6.1 & 5.5 & 4.9 & 4.1 & 3.7 & 3.9 & 2.7 & 2.4 & 2.2 \\
\hline \multirow{2}{*}{ F11 } & $\%$ CDR & 3.9 & 6.6 & 10.7 & 17.3 & 21.7 & 33.4 & 45.1 & 60.7 & 76.5 & 89.8 \\
\hline & $\%$ RSD & 8.1 & 7.6 & 6.4 & 5.3 & 4.7 & 4.3 & 3.7 & 2.9 & 2.4 & 2.1 \\
\hline
\end{tabular}

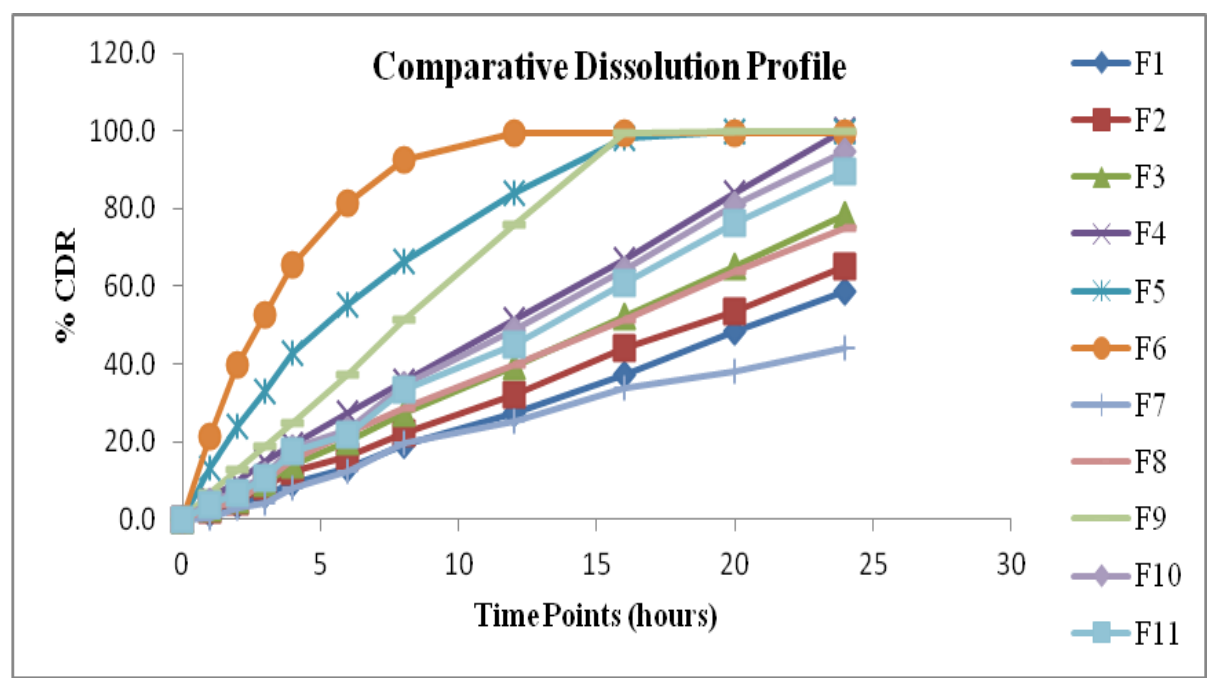

Figure 10: Comparative Dissolution Profile of Formulation Optimization

\subsubsection{Kinetic Modelling and Mechanism of Drug Release:}

The dissolution profile of the best batch was fitted to zero-order, first order, Higuchi and Koresmeyer models to ascertain the kinetics of drug release. It was concluded that the drug release from optimized formulation of Osmotic controlled release tablets was best explained by Zero order model. 
Table 18: Drug Release Kinetics

\begin{tabular}{|l|l|l|l|l|}
\hline Formulation Code & Higuchi Plot $\left(\mathbf{R}^{2}\right)$ & Zero order $\left(\mathbf{R}^{2}\right)$ & $\begin{array}{l}\text { Koresmeyer- } \\
\text { peppas }\left(\mathbf{R}^{2}\right)\end{array}$ & First order $\left(\mathbf{R}^{2}\right)$ \\
\hline F1 & 0.9822 & 0.9995 & 0.9980 & 0.9066 \\
\hline F2 & 0.9866 & 0.9994 & 0.9972 & 0.9075 \\
\hline F3 & 0.9871 & 0.9996 & 0.9978 & 0.9154 \\
\hline F4 & 0.9866 & 0.9998 & 0.9998 & 0.9289 \\
\hline F5 & 0.9829 & 0.9405 & 0.9854 & 0.8496 \\
\hline F6 & 0.9022 & 0.8148 & 0.9352 & 0.7361 \\
\hline F7 & 0.9951 & 0.9910 & 0.9766 & 0.8318 \\
\hline F8 & 0.9923 & 0.9978 & 0.9936 & 0.8946 \\
\hline F9 & 0.9834 & 0.9635 & 0.9935 & 0.8882 \\
\hline F10 & 0.9869 & 0.9991 & 0.9974 & 0.9256 \\
\hline F11 & 0.9869 & 0.9989 & 0.9975 & 0.9193 \\
\hline
\end{tabular}

\subsection{Optimization of Formulation by Using Experimental Design}

\section{$3^{2}$ Full Factorial Design:}

It is desirable to develop an acceptable pharmaceutical formulation in shortest possible time using minimum number of man-hours and raw materials. Traditionally pharmaceutical formulations are developed by changing one variable at a time approach. The method is time consuming in nature and requires a lot of imaginative efforts. Moreover, it may be difficult to develop an ideal formulation using this classical technique since the joint effects of independent variables are not considered. It is therefore very essential to understand the complexity of pharmaceutical formulations by using established statistical tools such as factorial design. In addition to the art of formulation, the technique of factorial design is an effective method of indicating the relative significance of a number of variables and their interactions.

The number of experiments required for these studies is dependent on the number of independent variables selected. The response $(Y i)$ is measured for each trial.

$Y=b_{0}+b_{1} X_{1}+b_{2} x_{2}+b_{12} x_{1} x_{2}+b_{11} x_{12}+b_{22} x_{22}$

Where $\mathrm{Y}$ is the dependent variable, b0 is the arithmetic mean response of the nine runs and bi is the estimated coefficient for the factor $\mathrm{Xi}$. The main effects (X1 and $\mathrm{X} 2$ ) represent the average result of changing one factor at a time from its low to high value. The interaction terms (X1X2) show how the response changes when two factors are simultaneously changed.

The polynomial equation can be used to draw conclusion after considering the magnitude of coefficient and the mathematical sign it carries, i.e., positive or negative. The high values of correlation coefficient for the dependent variables indicate a good fit. The equation 1 may be used to obtain estimate of the response because small error of variance was noticed in the replicates. 
Table 19: Design Table

\begin{tabular}{|c|c|c|c|}
\hline \multicolumn{4}{|l|}{ Full Factorial Design } \\
\hline Batch No. & \multicolumn{2}{|c|}{$\begin{array}{l}\text { X1 } \\
\text { Amount of Povidone } \mathrm{K} 30(\mathrm{mg})\end{array}$} & $\begin{array}{l}\mathrm{X} 2 \\
\text { Amount of } \mathrm{NaCl}(\mathrm{mg})\end{array}$ \\
\hline A1 & \multicolumn{2}{|l|}{-1} & -1 \\
\hline A2 & \multicolumn{2}{|l|}{-1} & 0 \\
\hline A3 & \multicolumn{2}{|l|}{-1} & +1 \\
\hline A4 & \multicolumn{2}{|l|}{0} & -1 \\
\hline A5 & \multicolumn{2}{|c|}{0} & 0 \\
\hline A6 & \multicolumn{2}{|c|}{0} & +1 \\
\hline A7 & \multicolumn{2}{|c|}{+1} & -1 \\
\hline A8 & \multicolumn{2}{|l|}{+1} & 0 \\
\hline A9 & \multicolumn{2}{|l|}{+1} & +1 \\
\hline \multicolumn{4}{|c|}{ Translation of coded level in actual limit } \\
\hline \multirow{2}{*}{\multicolumn{2}{|c|}{ Independent variables }} & \multicolumn{2}{|l|}{ Real Value } \\
\hline & & Low (-1) & High (+1) \\
\hline \multicolumn{2}{|l|}{ Amount of Povidone K 30 (mg) } & 1 & 4 \\
\hline Amount of $\mathrm{NaCl}(\mathrm{mg})$ & & 5 & 35 \\
\hline
\end{tabular}

All 9 batches were evaluated for \%Drug Release at 6 hours and 24 hours $\left(Y_{1}, Y_{2}\right)$ to find out effect of both the parameters $\left(X_{1}, X_{2}\right)$ on the films.

Independent variables:

$\mathrm{X}_{1}$ - Amount of Povidone $\mathrm{K} 30$ (mg)

$\mathrm{X}_{2}$ - Amount of $\mathrm{NaCl}(\mathrm{mg})$

Dependent Variables:

$\mathrm{Y}_{1}-\%$ Drug Release at 6 hours

$\mathrm{Y}_{2}-\%$ Drug Release at 24 hours

\subsection{Formulation of Factorial Batches}

Tablets were prepared using the same procedure as preliminary batches as per formula table given below:

Table 20: Formulation Table of Factorial Batches

\begin{tabular}{|l|l|l|l|l|l|l|l|l|l|l|}
\hline cal & Ingredients & A1 & A2 & A3 & A4 & A5 & A6 & A7 & A8 & A9 \\
\hline & Core & Mg/tab & \multicolumn{7}{|c|}{$\mid$} \\
\hline 1 & Carvedilol Phosphate & 54.24 & 54.24 & 54.24 & 54.24 & 54.24 & 54.24 & 54.24 & 54.24 & 54.24 \\
\hline 2 & Microcrystalline Cellulose & 36.26 & 34.76 & 33.26 & 21.26 & 19.76 & 18.26 & 6.26 & 4.76 & 3.26 \\
\hline 3 & Pregelatinized Starch & 20.00 & 20.00 & 20.00 & 20.00 & 20.00 & 20.00 & 20.00 & 20.00 & 20.00 \\
\hline 4 & Low-substituted HPC & 15.00 & 15.00 & 15.00 & 15.00 & 15.00 & 15.00 & 15.00 & 15.00 & 15.00 \\
\hline 5 & Sodium Chloride & $\mathbf{5 . 0 0}$ & $\mathbf{5 . 0 0}$ & $\mathbf{5 . 0 0}$ & $\mathbf{2 0 . 0 0}$ & $\mathbf{2 0 . 0 0}$ & $\mathbf{2 0 . 0 0}$ & $\mathbf{3 5 . 0 0}$ & $\mathbf{3 5 . 0 0}$ & $\mathbf{3 5 . 0 0}$ \\
\hline
\end{tabular}




\begin{tabular}{|c|c|c|c|c|c|c|c|c|c|c|}
\hline 6 & Mannitol & 75.00 & 75.00 & 75.00 & 75.00 & 75.00 & 75.00 & 75.00 & 75.00 & 75.00 \\
\hline 7 & Talc & 5.00 & 5.00 & 5.00 & 5.00 & 5.00 & 5.00 & 5.00 & 5.00 & 5.00 \\
\hline \multirow[t]{2}{*}{8} & Magnesium Stearate & 10.00 & 10.00 & 10.00 & 10.00 & 10.00 & 10.00 & 10.00 & 10.00 & 10.00 \\
\hline & Coat & \multicolumn{9}{|c|}{$\mathrm{Mg} / \mathrm{tab}$} \\
\hline & Cellulose Acetate 398-10 & 25.00 & 25.00 & 25.00 & 25.00 & 25.00 & 25.00 & 25.00 & 25.00 & 25.00 \\
\hline & PEG 400 & 3.50 & 3.50 & 3.50 & 3.50 & 3.50 & 3.50 & 3.50 & 3.50 & 3.50 \\
\hline \multirow[t]{2}{*}{3} & Povidone K30 & 1.00 & 2.50 & 4.00 & 1.00 & 2.50 & 4.00 & 1.00 & 2.50 & 4.00 \\
\hline & Total & 50.00 & 250.00 & 250.00 & 250.00 & 250.00 & 250.0 & 250.00 & 250. & 250.00 \\
\hline
\end{tabular}

\subsection{Evaluation of Prepared OROS Tablets}

Prepared batches of Carvedilol Phosphate OROS Tablets were evaluated as per the responses selected in the study design.

\section{Table 21: Results of Post-Compression Parameters of Factorial Batches}

\begin{tabular}{|l|l|l|l|l|l|}
\hline Formulations & Weight $(\mathrm{mg})$ & Thickness $(\mathrm{mm})$ & $\begin{array}{l}\text { Hardness } \\
\left(\mathrm{kg} / \mathrm{cm}^{2}\right)\end{array}$ & $\begin{array}{l}\text { Friability } \\
(\%)\end{array}$ & Assay (\%) \\
\hline A1 & $250.4 \pm 3.9$ & $4.62 \pm 0.06$ & $15.5 \pm 0.5$ & $0.032 \pm 0.02$ & $100.1 \pm 0.5$ \\
\hline A2 & $251.2 \pm 3.2$ & $4.61 \pm 0.08$ & $15.2 \pm 0.4$ & $0.042 \pm 0.03$ & $100.3 \pm 0.8$ \\
\hline A3 & $250.9 \pm 4.2$ & $4.60 \pm 0.09$ & $15.0 \pm 0.6$ & $0.043 \pm 0.04$ & $99.8 \pm 0.7$ \\
\hline A4 & $249.7 \pm 5.2$ & $4.59 \pm 0.07$ & $14.8 \pm 0.9$ & $0.027 \pm 0.05$ & $99.9 \pm 0.9$ \\
\hline A5 & $250.9 \pm 4.1$ & $4.60 \pm 0.08$ & $14.7 \pm 0.8$ & $0.031 \pm 0.06$ & $98.8 \pm 1.2$ \\
\hline A6 & $250.4 \pm 5.3$ & $4.62 \pm 0.09$ & $14.9 \pm 0.6$ & $0.035 \pm 0.05$ & $98.7 \pm 1.6$ \\
\hline A7 & $248.3 \pm 5.2$ & $4.61 \pm 0.08$ & $15.2 \pm 0.7$ & $0.040 \pm 0.06$ & $99.9 \pm 0.9$ \\
\hline A8 & $251.3 \pm 4.9$ & $4.62 \pm 0.09$ & $15.3 \pm 0.8$ & $0.032 \pm 0.07$ & $100.2 \pm 0.3$ \\
\hline A9 & $250.7 \pm 3.7$ & $4.62 \pm 0.07$ & $15.3 \pm 0.9$ & $0.029 \pm 0.08$ & $100.0 \pm 0.6$ \\
\hline
\end{tabular}


Table 22: Results of Dissolution Studies of Factorial Batches

\begin{tabular}{|c|c|c|c|c|c|c|c|c|c|c|c|}
\hline \multirow[b]{2}{*}{ Formulations } & \multicolumn{11}{|c|}{$\begin{array}{l}\text { \% Cumulative Drug Release in } 900 \mathrm{ml}, 0.1 \mathrm{~N} \mathrm{HCl} \text {, followed by } \mathrm{pH} 6.8 \text { phosphate } \\
\text { buffer after } 2 \text { hours at } 50 \text { RPM Paddle }\end{array}$} \\
\hline & & $\begin{array}{l}1 \\
\text { hour }\end{array}$ & $\begin{array}{l}2 \\
\text { hours }\end{array}$ & 3 & $\begin{array}{l}4 \\
\text { hours }\end{array}$ & \begin{tabular}{|l}
6 \\
hours
\end{tabular} & $\begin{array}{l}8 \\
\text { hours }\end{array}$ & $\begin{array}{l}12 \\
\text { hours }\end{array}$ & \begin{tabular}{|l}
16 \\
hours
\end{tabular} & \begin{tabular}{|l}
20 \\
hours
\end{tabular} & \begin{tabular}{l|l|}
24 \\
hours
\end{tabular} \\
\hline \multirow{2}{*}{ A1 } & $\%$ CDR & 2.1 & 4.9 & 6.2 & 7.9 & 9.8 & 18.9 & 29.8 & 35.7 & 42.9 & 50.2 \\
\hline & $\%$ RSD & 6.6 & 4.3 & 3.6 & 2.0 & 2.1 & 2.4 & 2.0 & 1.8 & 1.3 & 1.2 \\
\hline \multirow{2}{*}{ A2 } & $\%$ CDR & 5.4 & 9.8 & 14.2 & 17.3 & 22.3 & 31.2 & 48.7 & 56.9 & 62.8 & 69.5 \\
\hline & $\%$ RSD & 9.7 & 7.2 & 6.2 & 4.6 & 3.8 & 2.9 & 2.8 & 2.4 & 2.2 & 2.3 \\
\hline \multirow{2}{*}{ A3 } & $\% \mathrm{CDR}$ & 7.5 & 13.1 & 20.3 & 25.1 & 35.2 & 43.7 & 61.3 & 69.8 & 75.2 & 81.3 \\
\hline & $\%$ RSD & 8.9 & 8.2 & 7.4 & 6.9 & 5.5 & 4.2 & 3.1 & 3.5 & 3.0 & 2.8 \\
\hline \multirow[b]{2}{*}{ A4 } & $\% \mathrm{CDR}$ & 4.2 & 8.7 & 12.9 & 15.2 & 18.9 & 28.9 & 35.8 & 45.9 & 56.8 & 70.2 \\
\hline & $\%$ RSD & 8.5 & 7.4 & 6.9 & 6.5 & 5.4 & 4.9 & 4.2 & 4.1 & 3.9 & 3.5 \\
\hline \multirow{2}{*}{ A5 } & $\%$ CDR & 13.0 & 23.9 & 33.1 & 42.7 & 55.4 & 66.6 & 84.1 & 98.3 & 99.7 & 99.9 \\
\hline & $\%$ RSD & 7.4 & 6.9 & 6.4 & 6.3 & 5.4 & 4.9 & 3.5 & 1.1 & 1.2 & 1.0 \\
\hline \multirow{2}{*}{$A 6$} & $\%$ CDR & 18.1 & 31.5 & 42.9 & 59.7 & 74.3 & 85.6 & 98.2 & 99.9 & 99.2 & 100.1 \\
\hline & $\%$ RSD & 6.9 & 5.4 & 5.9 & 4.8 & 3.9 & 3.1 & 2.9 & 1.2 & 1.1 & 1.3 \\
\hline \multirow{2}{*}{ A7 } & $\%$ CDR & 6.1 & 10.5 & 15.3 & 20.6 & 26.9 & 34.7 & 52.6 & 62.4 & 75.9 & 84.3 \\
\hline & $\%$ RSD & 8.2 & 8.3 & 7.9 & 7.1 & 6.2 & 6.0 & 5.1 & 4.9 & 3.3 & 2.4 \\
\hline \multirow[b]{2}{*}{ A8 } & $\%$ CDR & 29.9 & 48.2 & 61.7 & 71.6 & 86.7 & 93.7 & 98.9 & 100.2 & 99.9 & 100.3 \\
\hline & $\%$ RSD & 6.2 & 5.4 & 4.3 & 3.9 & 2.8 & 1.9 & 1.2 & 1.3 & 1.2 & 1.1 \\
\hline \multirow{2}{*}{ A9 } & $\%$ CDR & 35.3 & 52.9 & 68.9 & 77.6 & 92.7 & 99.7 & 100.1 & 100.0 & 100.3 & 100.2 \\
\hline & $\%$ RSD & 5.9 & 4.8 & 4.1 & 4.3 & 2.5 & 1.2 & 1.1 & 1.2 & 1.1 & 1.0 \\
\hline
\end{tabular}

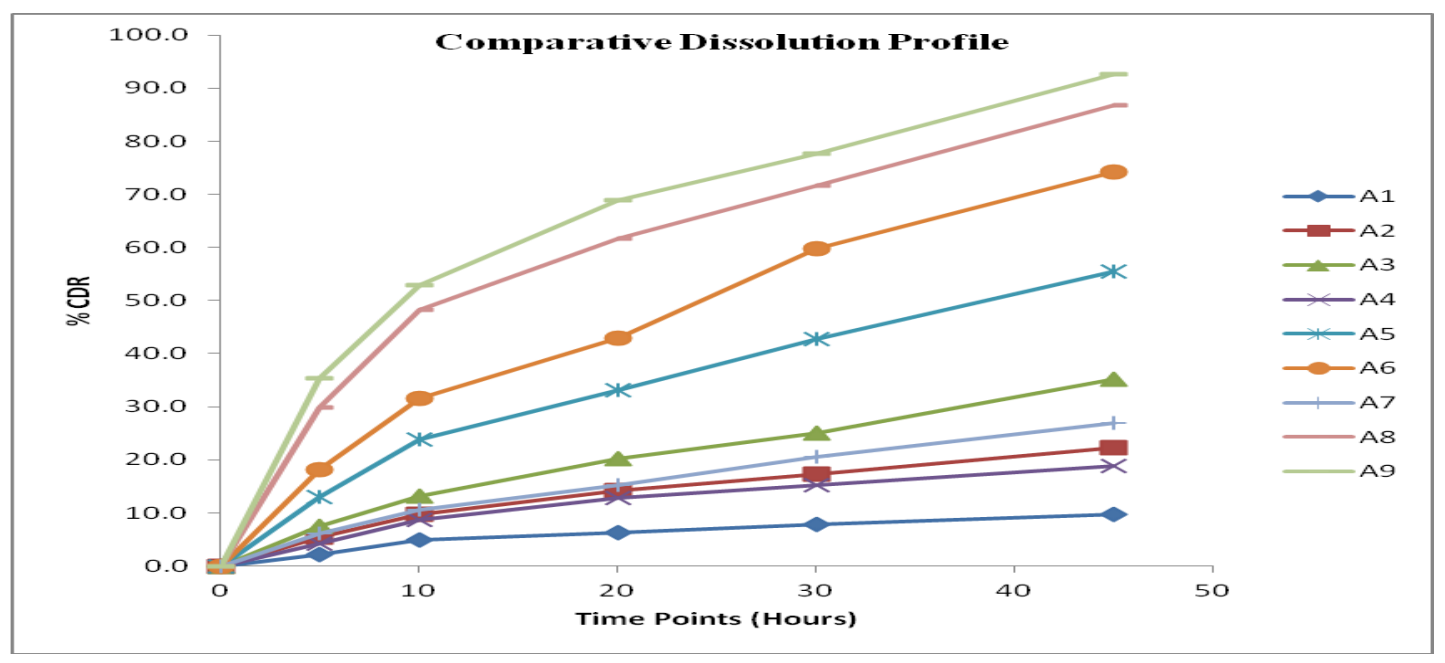

Figure 11: Comparative Dissolution Profile of Factorial Batches 


\subsection{Regression Analysis of Factorial Design}

Table 23: Regression Analysis

\begin{tabular}{|l|l|l|l|l|l|l|l|}
\hline $\begin{array}{l}\text { Std } \\
\text { Order }\end{array}$ & $\begin{array}{l}\text { Run } \\
\text { Order }\end{array}$ & Blocks & $\begin{array}{l}\text { Center } \\
\text { Point }\end{array}$ & $\begin{array}{l}\text { Level of Sodium } \\
\text { Chloride }(\mathbf{m g})\end{array}$ & $\begin{array}{l}\text { Level of Povidone } \\
\text { K30 (mg) }\end{array}$ & $\begin{array}{l}\text { Drug Release } \\
\text { at } \mathbf{6} \text { hours }\end{array}$ & $\begin{array}{l}\text { Drug Release } \\
\text { at 24 hours }\end{array}$ \\
\hline 1 & 1 & 1 & 1 & 5 & 1.0 & 9.8 & 50.2 \\
\hline 2 & 2 & 1 & 1 & 5 & 2.5 & 22.3 & 69.5 \\
\hline 3 & 3 & 1 & 1 & 5 & 4.0 & 35.2 & 81.3 \\
\hline 4 & 4 & 1 & 1 & 20 & 1.0 & 18.9 & 70.2 \\
\hline 5 & 5 & 1 & 1 & 20 & 2.5 & 55.4 & 99.9 \\
\hline 6 & 6 & 1 & 1 & 20 & 4.0 & 74.3 & 100.1 \\
\hline 7 & 7 & 1 & 1 & 35 & 1.0 & 26.9 & 84.3 \\
\hline 8 & 8 & 1 & 1 & 35 & 2.5 & 86.7 & 100.3 \\
\hline 9 & 9 & 1 & 1 & 35 & 4.0 & 92.7 & 100.2 \\
\hline
\end{tabular}

Table 24: ANOVA TABLE

\begin{tabular}{|l|l|l|l|l|l|l|}
\hline \multicolumn{2}{|l|}{ Analysis of Variance for \%Drug Release at 6 hours } \\
\hline Source & DF & Seq SS & Adj MS & F Value & P Value & Remarks \\
\hline Main Effects & 2 & 6802.1 & 3401.0 & 28.48 & 0.002 & Significant \\
\hline Level of Sodium Chloride (mg) & 1 & 3220.2 & 3220.2 & 26.97 & 0.003 & Significant \\
\hline Level of Povidone K30 (mg) & 1 & 3581.9 & 3581.9 & 30.00 & 0.003 & Significant \\
\hline 2-Way Interactions & 1 & 408.0 & 408.0 & 3.42 & 0.124 & $\begin{array}{l}\text { Non- } \\
\text { Significant }\end{array}$ \\
\hline $\begin{array}{l}\text { Level of Sodium Chloride } \\
\text { Level of Povidone K30 }\end{array}$ & 1 & 408.0 & 408.0 & 3.42 & 0.124 & $\begin{array}{l}\text { Non- } \\
\text { Significant }\end{array}$ \\
\hline Residual Error & 5 & 597.0 & 1194 & - & - & - \\
\hline Total & 8 & 7807.1 & - & - & - & - \\
\hline
\end{tabular}

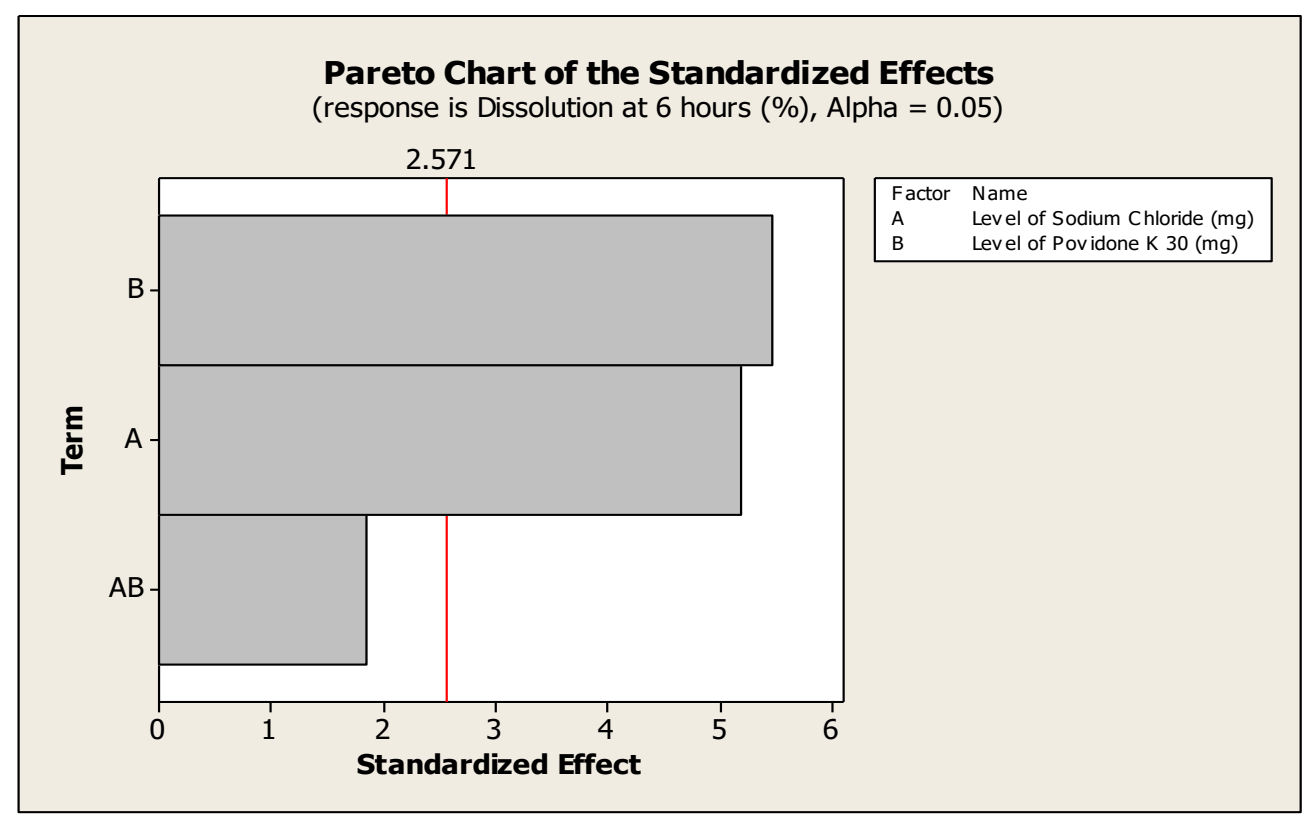

Figure 12: Pareto Chart for Drug Release at 6 hours 


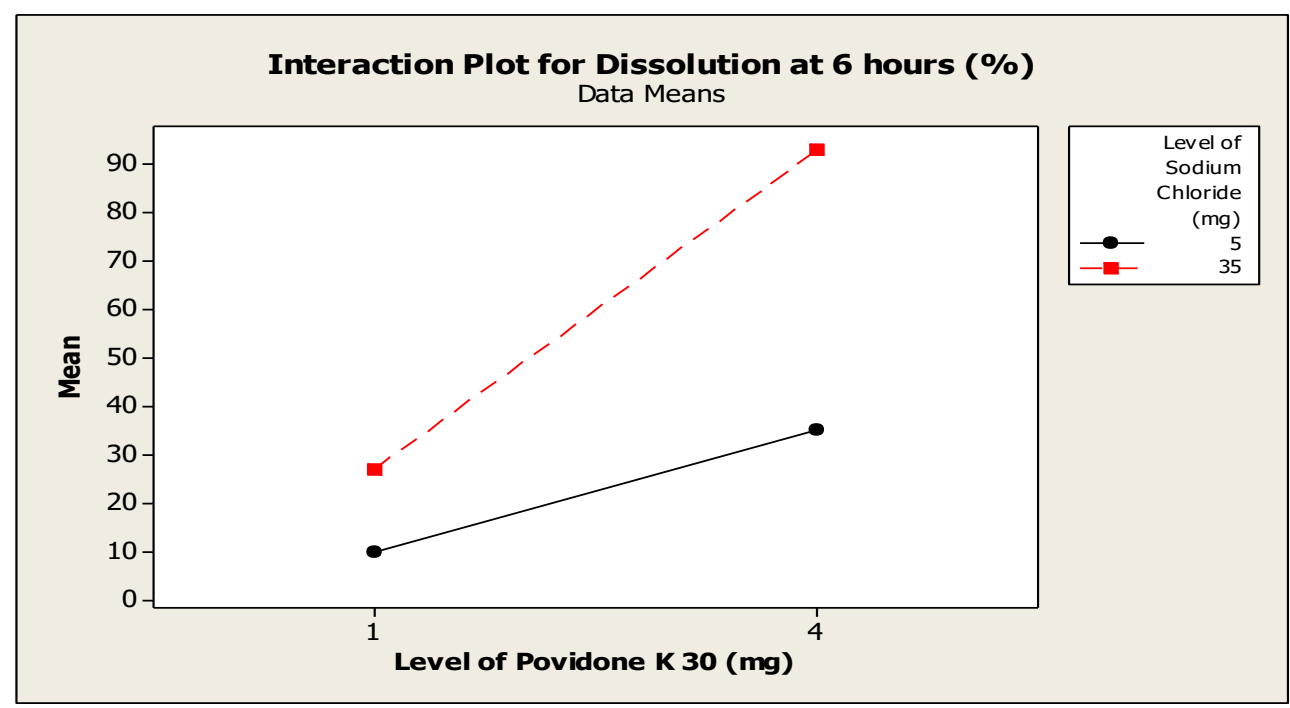

Figure 13: Interaction Plot for Drug Release at 6 hours

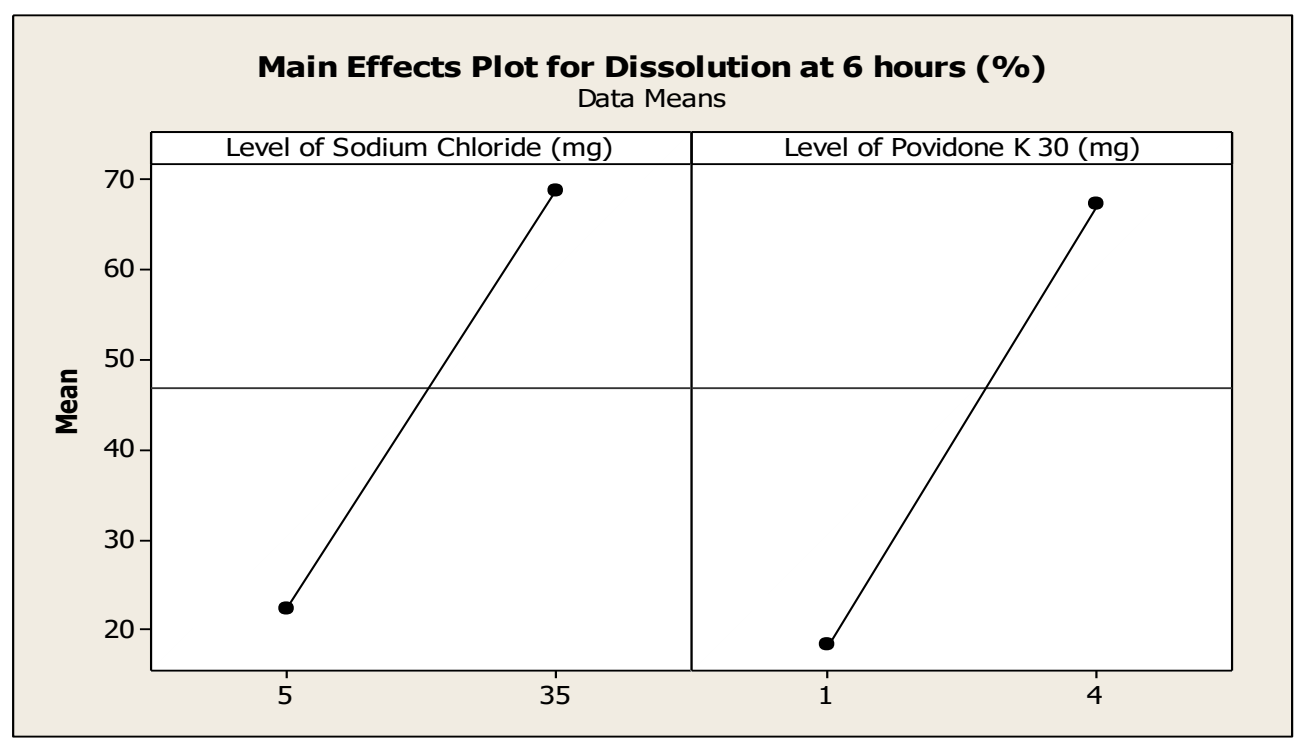

Figure 14: Main Effects Plot for \% Drug Release at 6 hours 


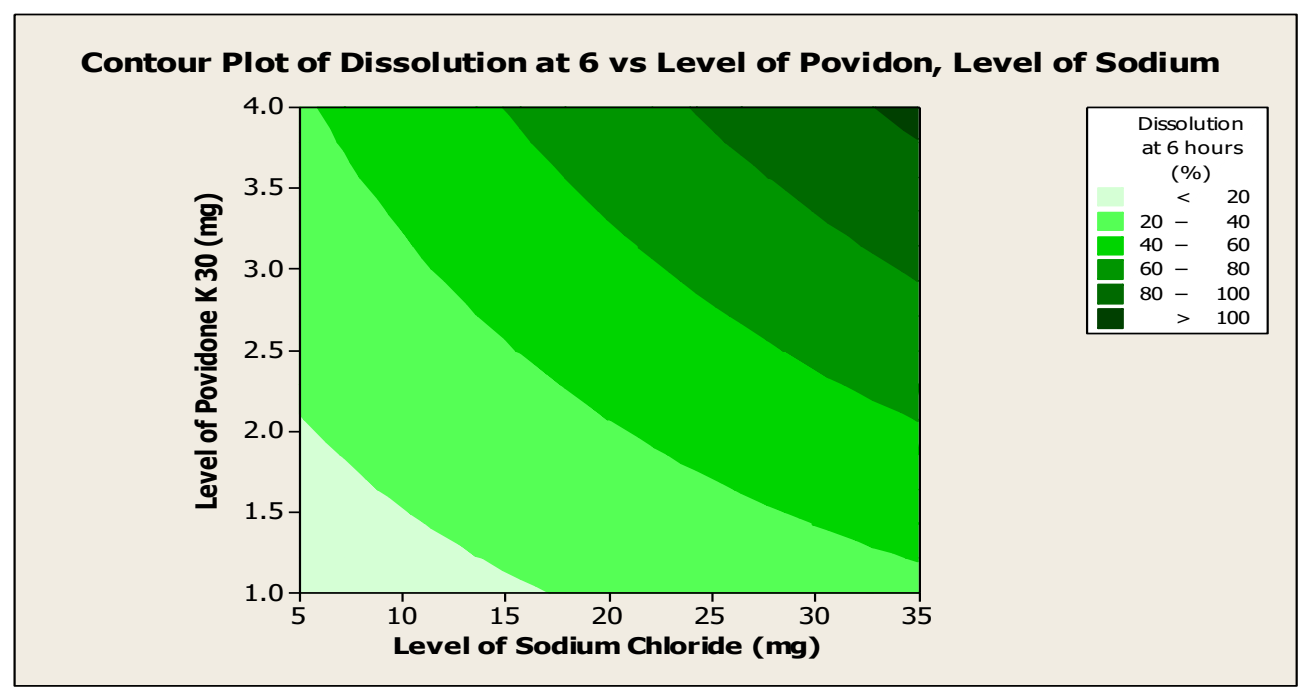

Figure 15: Contour Plot of Drug Release at 6 hours

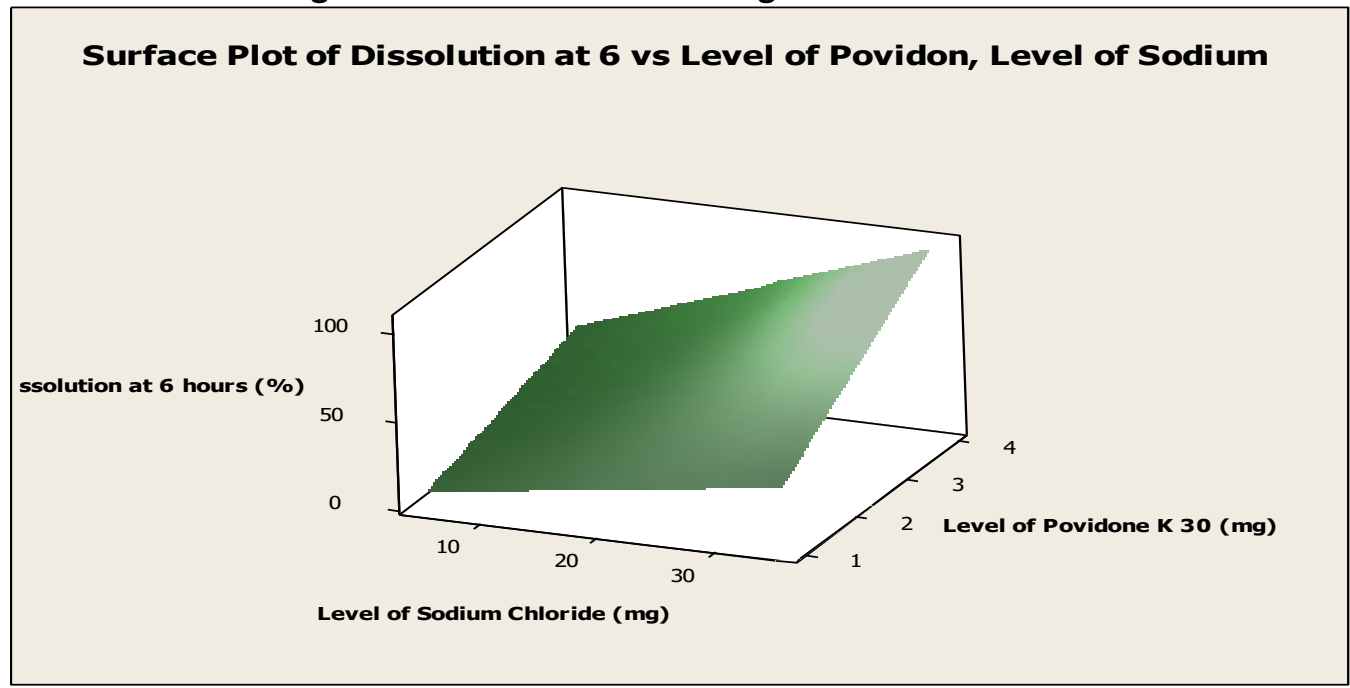

Figure 16: Surface Plot of Drug Release at 6 hours

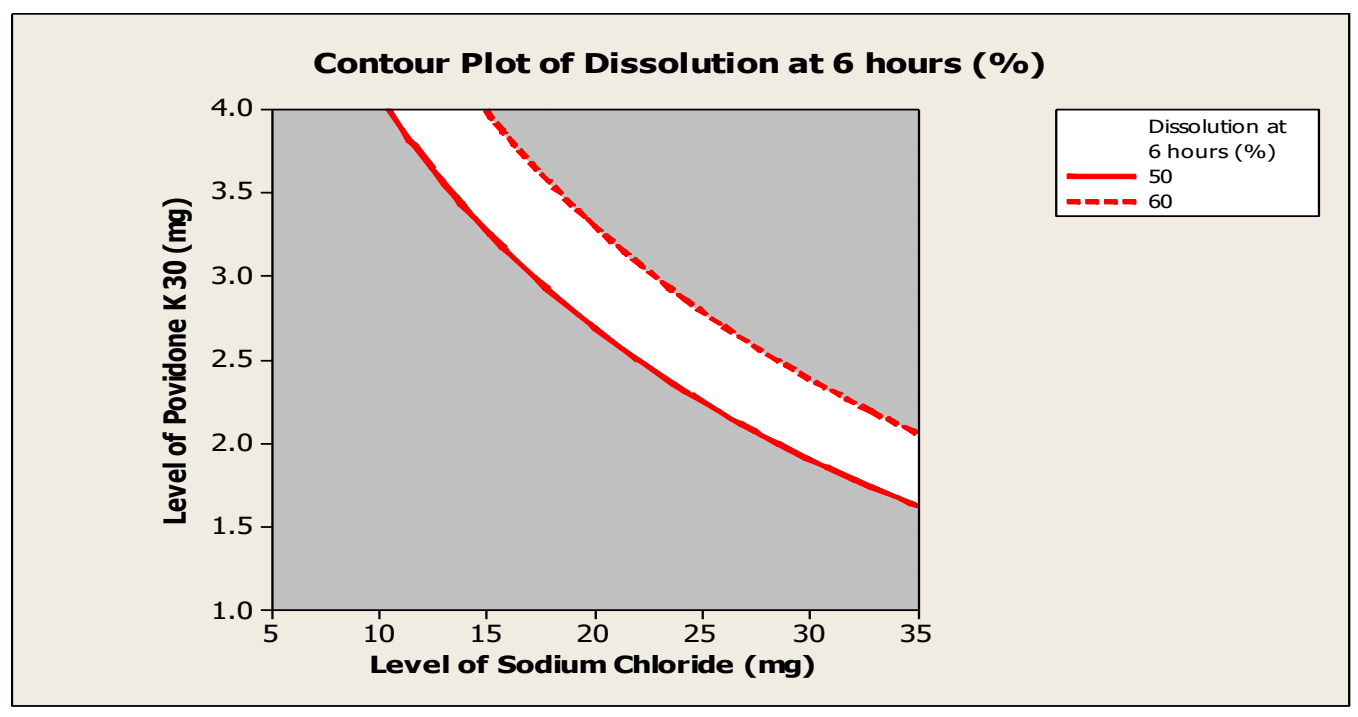

Figure 17: Contour Plot of Drug Release at 6 hours 
Table 25: ANOVA Table of Drug Release at 12 hours

\begin{tabular}{|l|l|l|l|l|l|l|}
\hline \multicolumn{7}{|l|}{ Analysis of Variance for \%Drug Release at 24 hours } \\
\hline Source & DF & Seq SS & Adj MS & F Value & P Value & Remarks \\
\hline Main Effects & 2 & 2156.01 & 1078.00 & 14.30 & 0.009 & Significant \\
\hline Level of Sodium Chloride (mg) & 1 & 1170.41 & 1170.41 & 15.53 & 0.011 & Significant \\
\hline Level of Povidone K30 (mg) & 1 & 985.60 & 985.60 & 13.08 & 0.015 & Significant \\
\hline 2-Way Interactions & 1 & 57.76 & 57.76 & 0.77 & 0.421 & $\begin{array}{l}\text { Non- } \\
\text { significant }\end{array}$ \\
\hline $\begin{array}{l}\text { Level of Sodium Chloride } \\
\text { Level of Povidone K30 }\end{array}$ & 1 & 57.76 & 57.76 & 0.77 & 0.421 & $\begin{array}{l}\text { Non- } \\
\text { Significant }\end{array}$ \\
\hline Residual Error & 5 & 376.89 & 75.38 & & & - \\
\hline Total & 8 & 2590.66 & & - & - & - \\
\hline
\end{tabular}

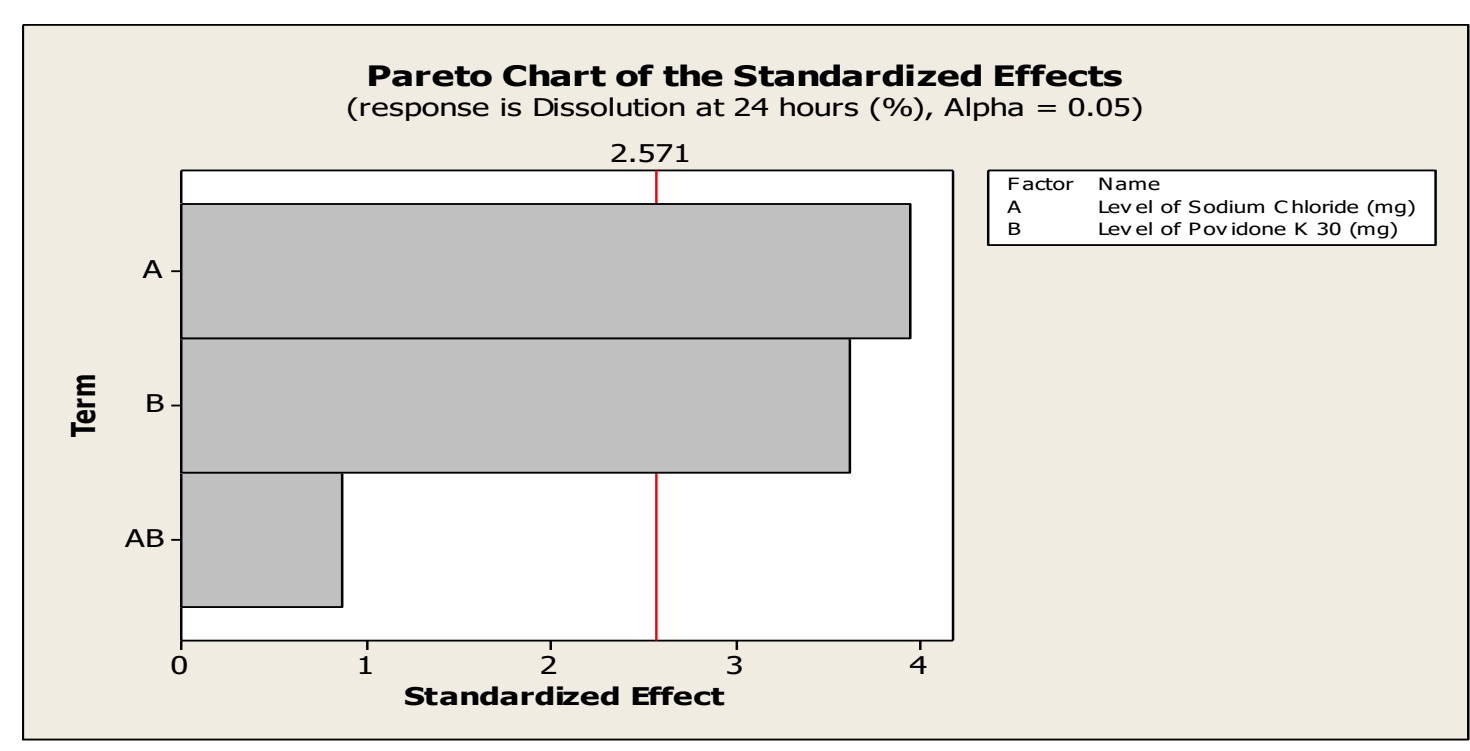

Figure 18: Pareto Chart for Drug Release at 24 hours

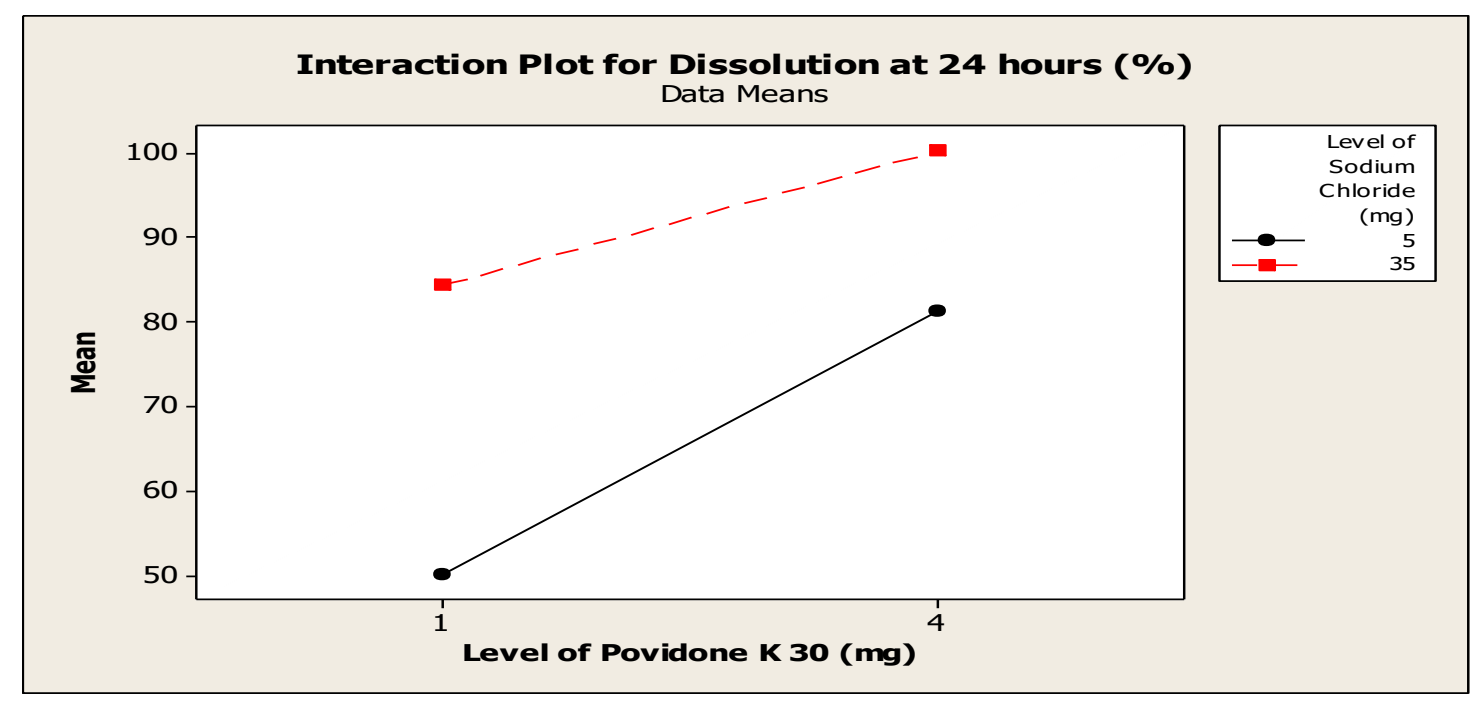

Figure 19: Interaction Plot for Drug Release at 24 hours 


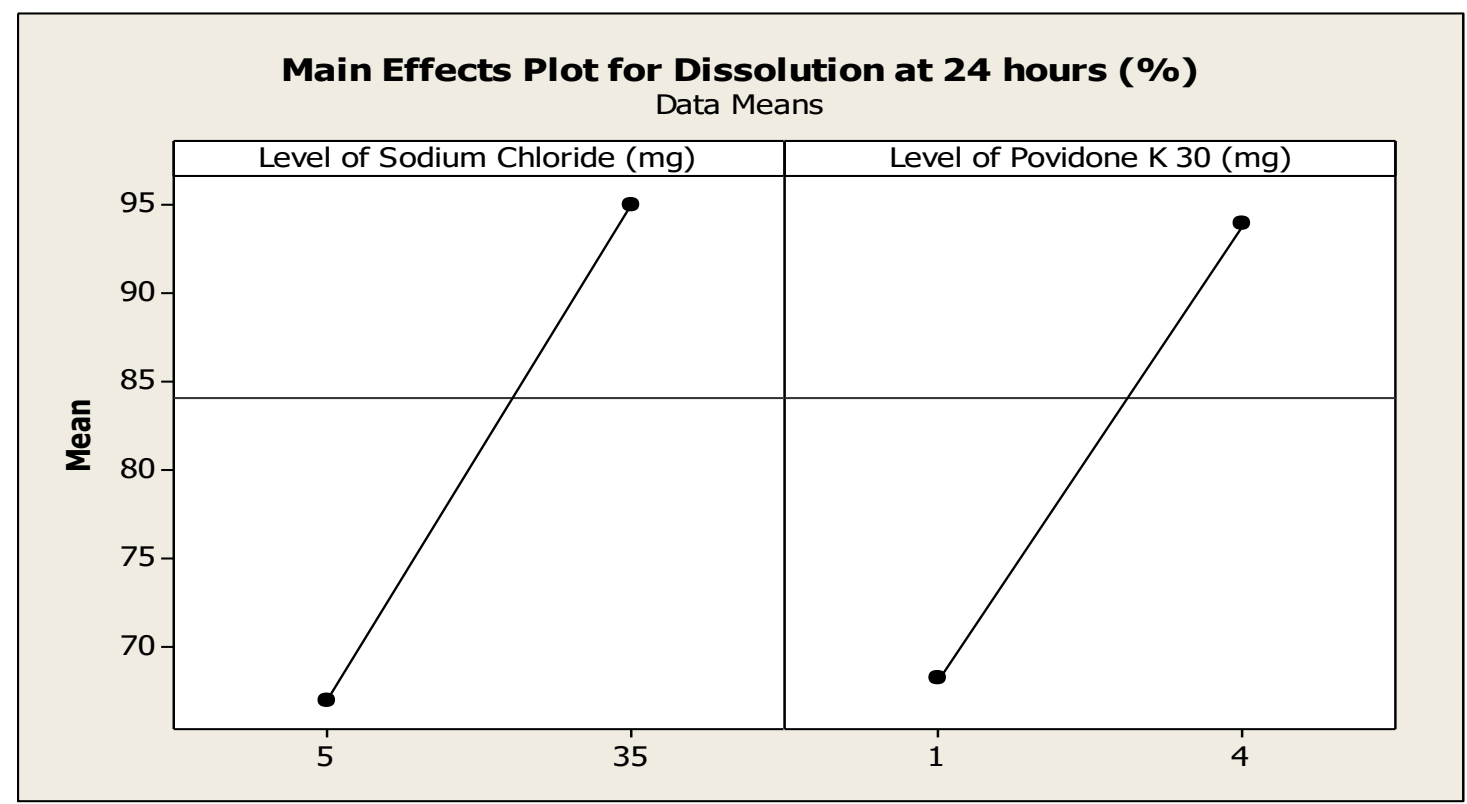

Figure 20: Main Effects Plot for Drug Release at $\mathbf{2 4}$ hours

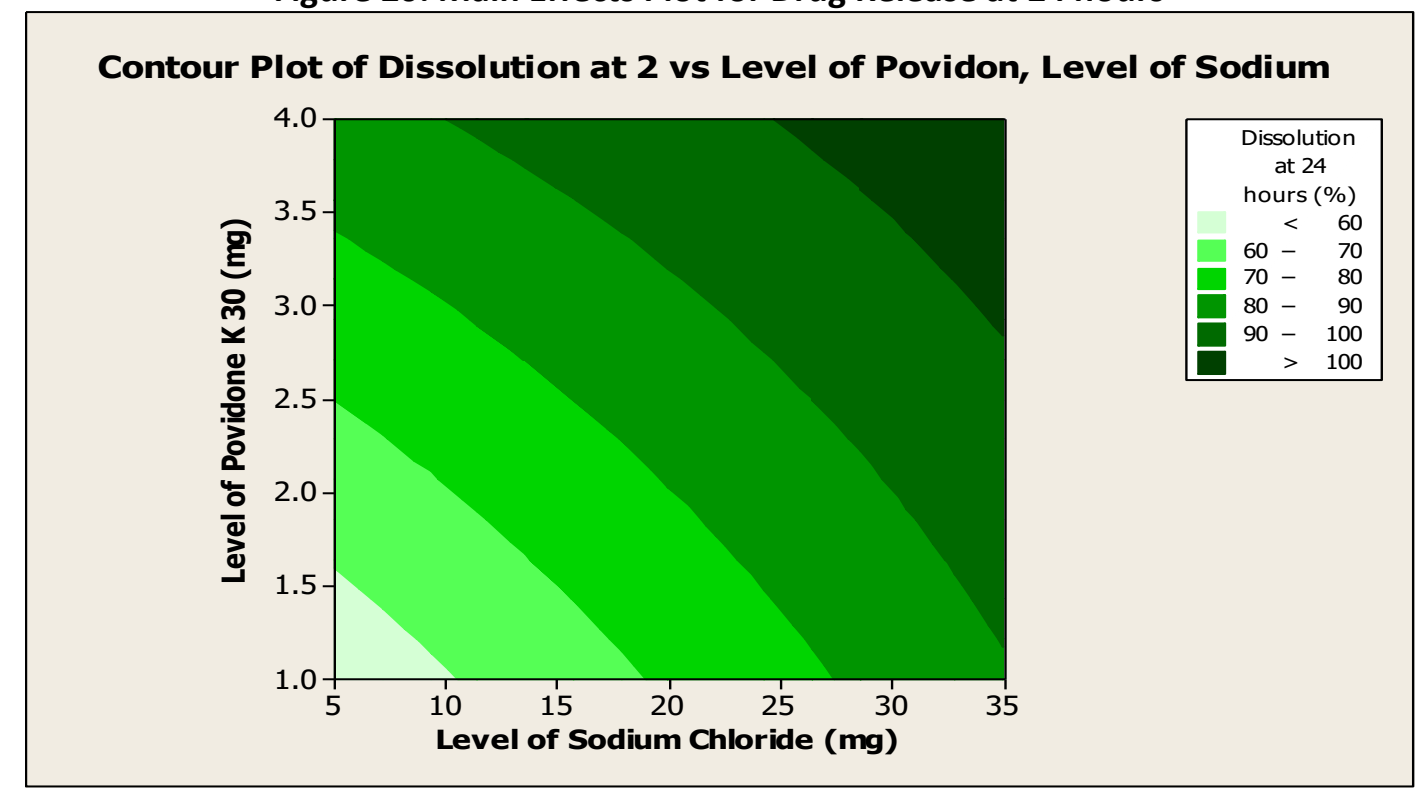

Figure 21: Contour Plot of Drug Release at 24 hours

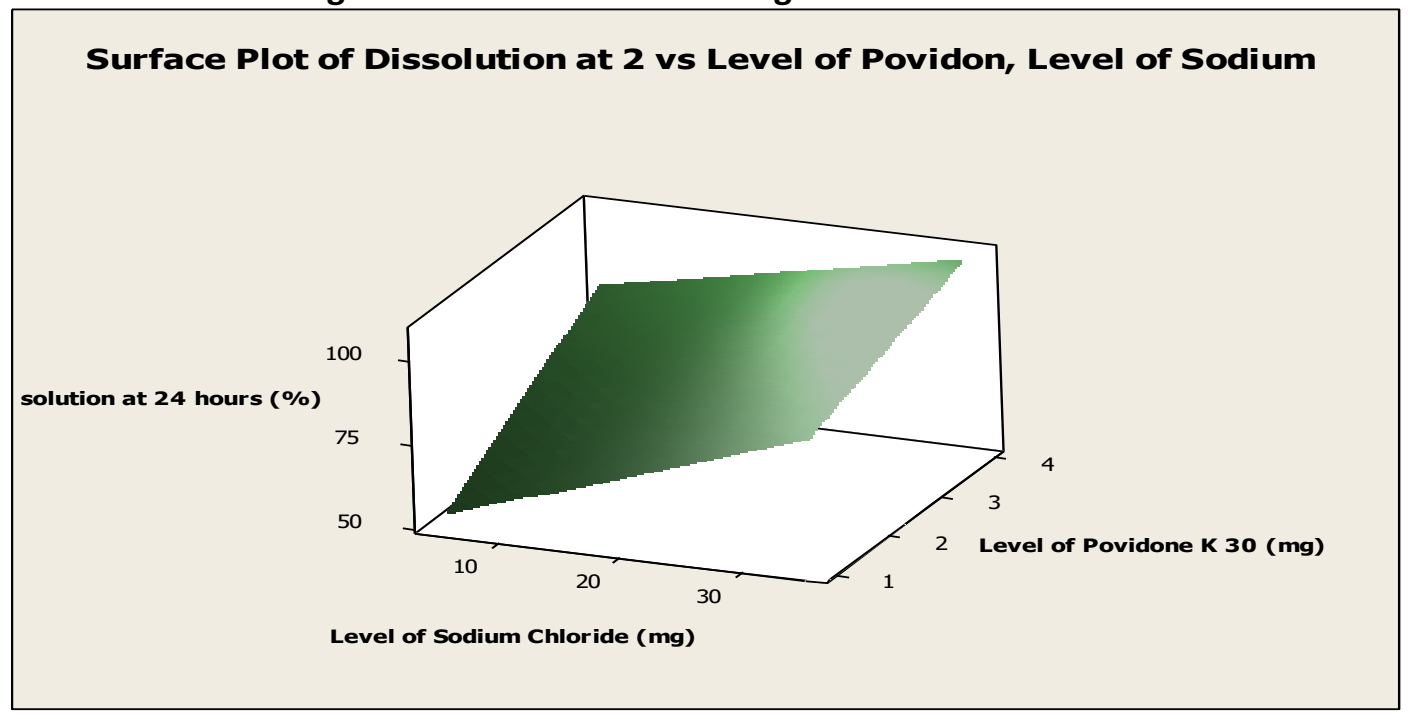

Figure 22: Surface Plot of Drug Release at 24 hours 


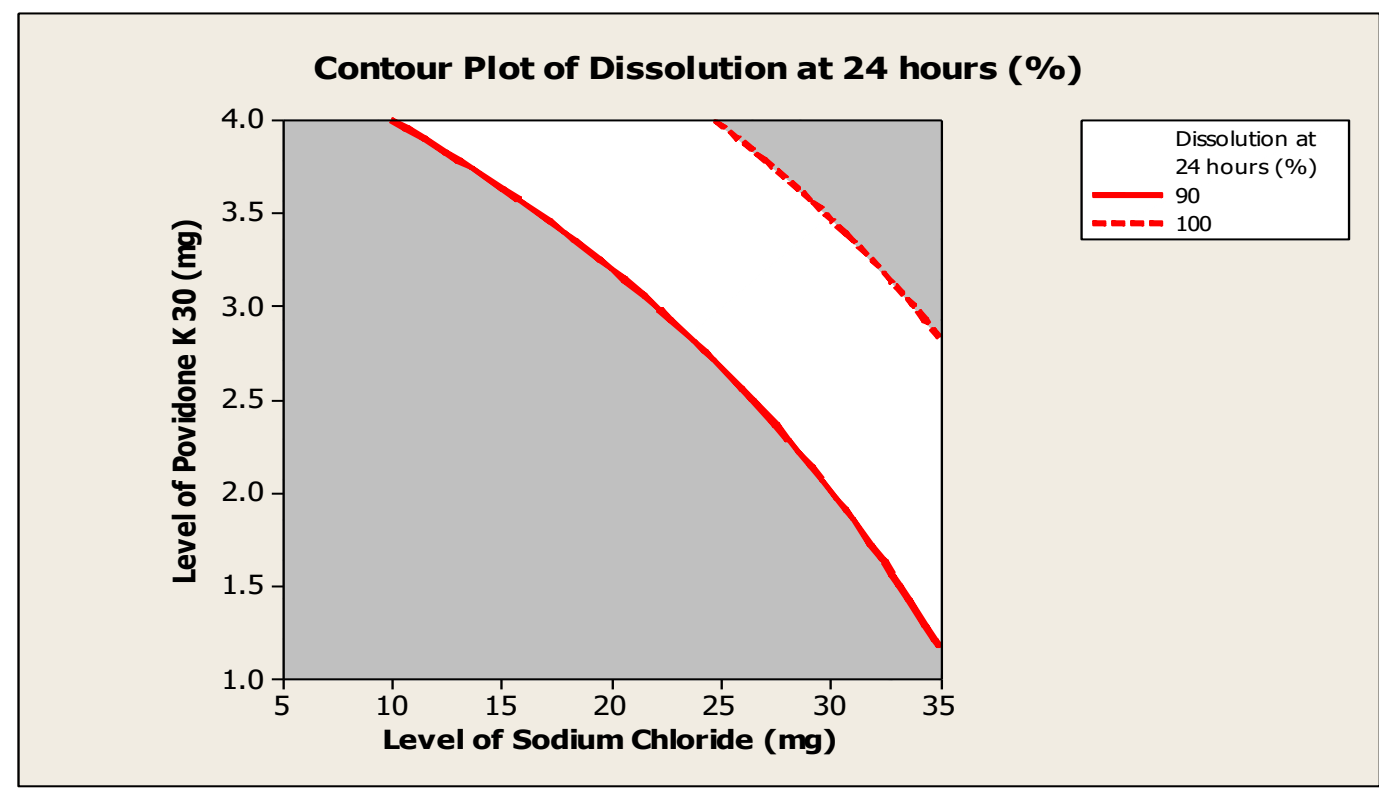

Figure 23: Contour Plot of Drug Release at 24 hours

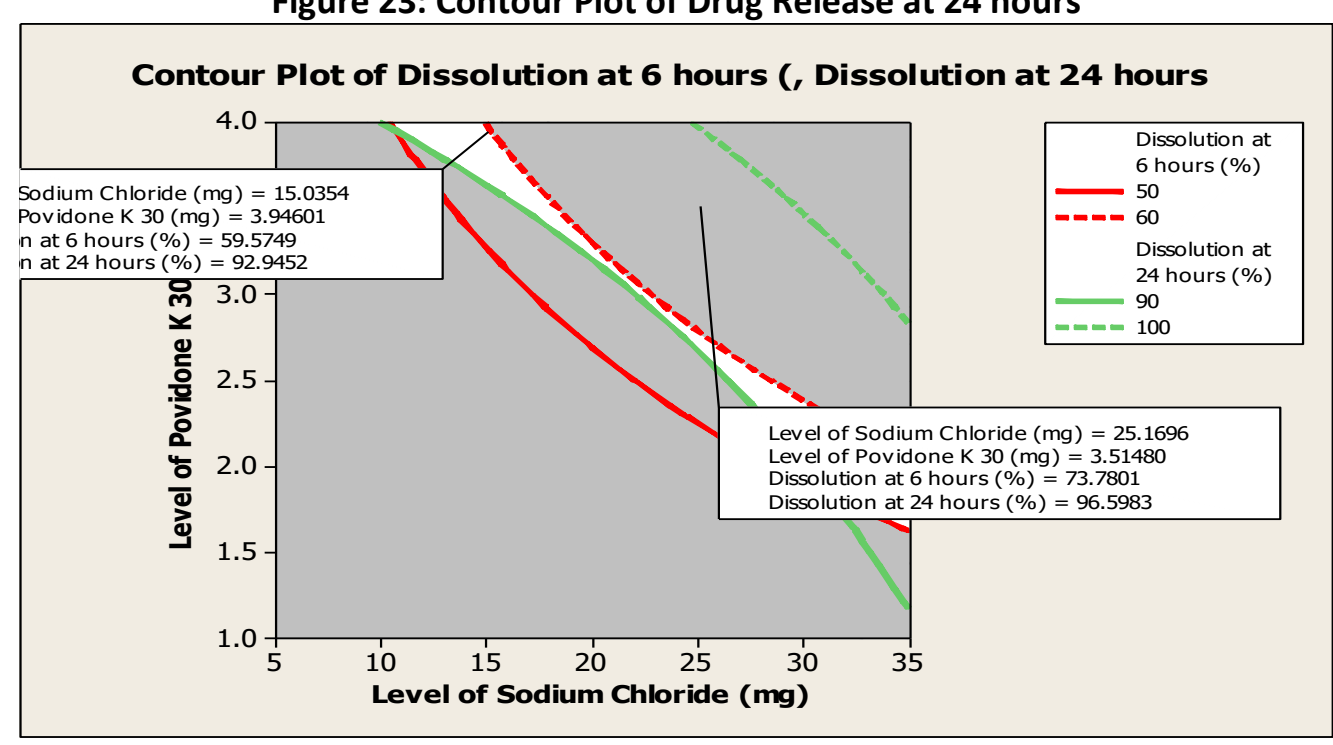

Figure 24: Contour Plot of Drug Release at 6 hours and 24 hours

\section{Validation of Optimized Formulation}

A checkpoint batch was designed accordance to the desirability function, as shown in Table below, to assess the validity of the prediction; a checkpoint batch $\mathrm{Z} 1$ and $\mathrm{Z} 2$ was prepared and evaluated under the same conditions as outlined for the other batches. The response data was compared with that of required data.

Table 26: Check Point Batches

\begin{tabular}{|c|c|c|c|c|c|c|c|c|}
\hline \multicolumn{9}{|c|}{ Check Point Batches } \\
\hline \multirow{2}{*}{ Batch } & \multirow{2}{*}{$\begin{array}{l}\text { Level of } \\
\mathrm{NaCl} \text { (mg) }\end{array}$} & \multirow{2}{*}{$\begin{array}{l}\text { Level } \\
\text { PVP } \\
\text { (mg) }\end{array}$} & \multicolumn{3}{|c|}{ of Drug Release at 6 hours } & \multicolumn{3}{|c|}{ Drug Release at 24 hours } \\
\hline & & & Predicted & Observed & Bias & Predicted & Observed & Bias \\
\hline $\mathrm{Z1}$ & 15 & 4 & 59.5 & 60.2 & 0.7 & 92.9 & 94.1 & 1.2 \\
\hline $\mathrm{Z2}$ & 25 & 3.5 & 73.7 & 74.2 & 0.5 & 96.6 & 98.2 & 1.6 \\
\hline
\end{tabular}

Discussion: The obtained response variables of check point batch compared with target response parameters. The bias for predicted versus observed responses was acceptable. 


\section{Optimized Batch}

Based on Factorial Design data, final optimized batch was selected from the contour plot to achieve desired \%Drug release at 6 hours and 24 hours. Complete analysis of the batches was done and recorded below.

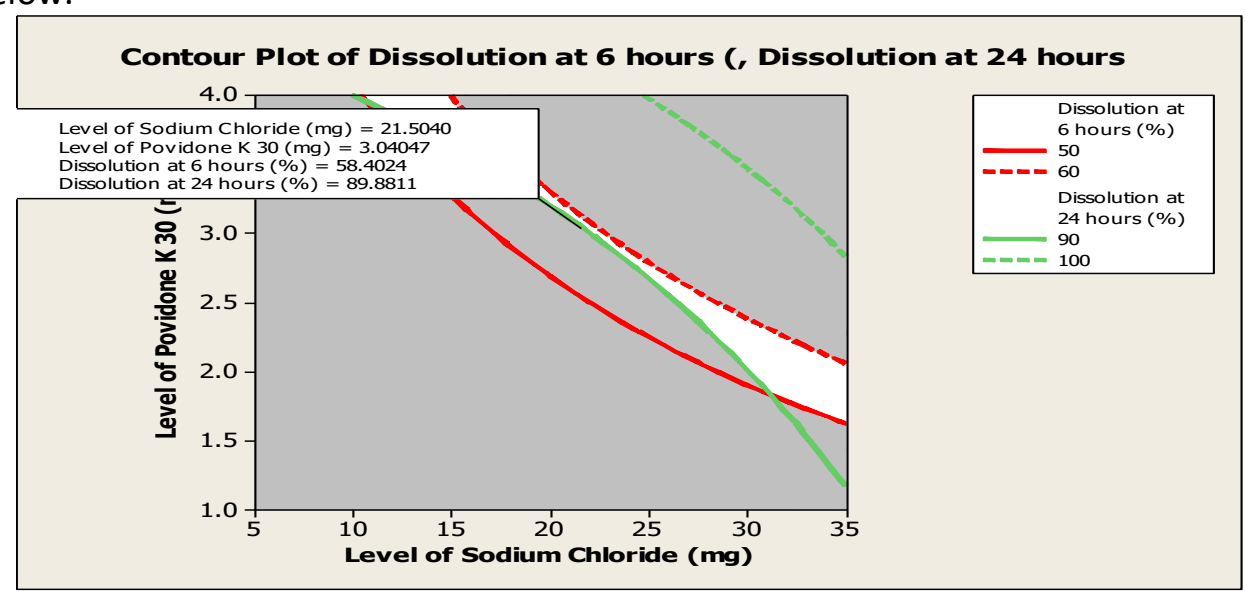

Figure 25: Contour Plot for Validation Batch 
Table 27: Formula and Results of Optimized Batch

\begin{tabular}{|l|l|l|}
\hline Sr. No. & Ingredients & $\mathbf{0 1}$ \\
\hline & Core & \\
\hline 1 & Carvedilol Phosphate & 54.24 \\
\hline 3 & Microcrystalline Cellulose & 17.76 \\
\hline 4 & Pregelatinized Starch & 20.00 \\
\hline 5 & Low-substituted HPC & 15.00 \\
\hline 6 & Sodium Chloride & $\mathbf{2 1 . 5}$ \\
\hline 7 & Mannitol & 75.00 \\
\hline 8 & Talc & 5.00 \\
\hline & Magnesium Stearate & 10.00 \\
\hline 1 & Coat & \\
\hline 2 & Cellulose Acetate 398-10 & 25.00 \\
\hline 3 & PEG 400 & 3.50 \\
\hline 4 & Povidone K30 & $\mathbf{3 . 0 0}$ \\
\hline 5 & Ethanol & Q.S. \\
\hline & Acetone & Q.S. \\
\hline & Total & $\mathbf{2 5 0 . 0 0}$ \\
\hline
\end{tabular}

\begin{tabular}{|c|c|c|}
\hline \multicolumn{3}{|c|}{ Results of Optimized Batch 01} \\
\hline \multicolumn{2}{|l|}{ Parameters } & Results \\
\hline \multicolumn{2}{|l|}{ Weight Variation (mg) } & $250.6 \pm 4.6$ \\
\hline \multicolumn{2}{|l|}{ Thickness (mm) } & $4.62 \pm 0.05$ \\
\hline \multicolumn{2}{|l|}{ Hardness $\left(\mathrm{kg} / \mathrm{cm}^{2}\right)$} & $15.2 \pm 0.7$ \\
\hline \multicolumn{2}{|l|}{ Friability (\%) } & $0.032 \pm 0.03$ \\
\hline \multicolumn{2}{|l|}{ Drug Content (\%) } & $100.3 \pm 0.2$ \\
\hline \multirow{11}{*}{ \% Drug Release } & Time (hours) & \% Drug Release \\
\hline & 1 & $18.6(8.2)$ \\
\hline & 2 & $32.7(6.9)$ \\
\hline & 3 & $41.8(5.4)$ \\
\hline & 4 & $52.1(3.5)$ \\
\hline & 6 & $61.9(4.4)$ \\
\hline & 8 & $69.8(3.9)$ \\
\hline & 12 & $81.6(3.1)$ \\
\hline & 16 & $88.9(2.2)$ \\
\hline & 20 & $92.7(1.9)$ \\
\hline & 24 & $94.3(1.7)$ \\
\hline
\end{tabular}

\subsection{Dissolution Comparison to Marketed Formulation:}

Optimized formulation obtained from Statistical Study was compared to Generic marketed product which is available as an Immediate Release Film coated tablet. 
Table 28: Dissolution Comparison with Marketed Product

\begin{tabular}{|c|c|c|c|c|c|c|c|c|c|c|c|}
\hline \multirow{2}{*}{ Formulations } & \multicolumn{11}{|c|}{$\begin{array}{l}\text { \% Cumulative Drug Release in } 900 \mathrm{ml}, 0.1 \mathrm{~N} \mathrm{HCl} \text {, followed by } \mathrm{pH} 6.8 \text { phosphate } \\
\text { buffer after } 2 \text { hours at } 50 \text { RPM Paddle }\end{array}$} \\
\hline & & $\begin{array}{l}1 \\
\text { hour }\end{array}$ & $\begin{array}{l}2 \\
\text { hours }\end{array}$ & $\begin{array}{l}3 \\
\text { hours }\end{array}$ & $\begin{array}{l}4 \\
\text { hours }\end{array}$ & $\begin{array}{l}6 \\
\text { hours }\end{array}$ & 8 & $\begin{array}{l}12 \\
\text { hours }\end{array}$ & $\begin{array}{l}16 \\
\text { hours }\end{array}$ & $\begin{array}{l}20 \\
\text { hours }\end{array}$ & 24 \\
\hline \multirow{2}{*}{01} & $\%$ CDR & 18.6 & 32.7 & 41.8 & 52.1 & 61.9 & 69.8 & 81.6 & 88.9 & 92.7 & 94.3 \\
\hline & $\%$ RSD & 8.2 & 6.9 & 5.4 & 3.5 & 4.4 & 3.9 & 3.1 & 2.2 & 1.9 & 1.7 \\
\hline \multirow{2}{*}{$\begin{array}{l}\text { Marketed } \\
\text { ormulation }\end{array}$} & $\%$ CDR & 99.8 & 99.9 & 99.9 & 100.1 & 99.8 & 100.2 & 100.3 & 99.8 & 99.8 & 99.9 \\
\hline & $\%$ RSD & 2.1 & 2.2 & 1.9 & 1.8 & 1.8 & 1.9 & 1.8 & 2.0 & 1.7 & 1.8 \\
\hline
\end{tabular}

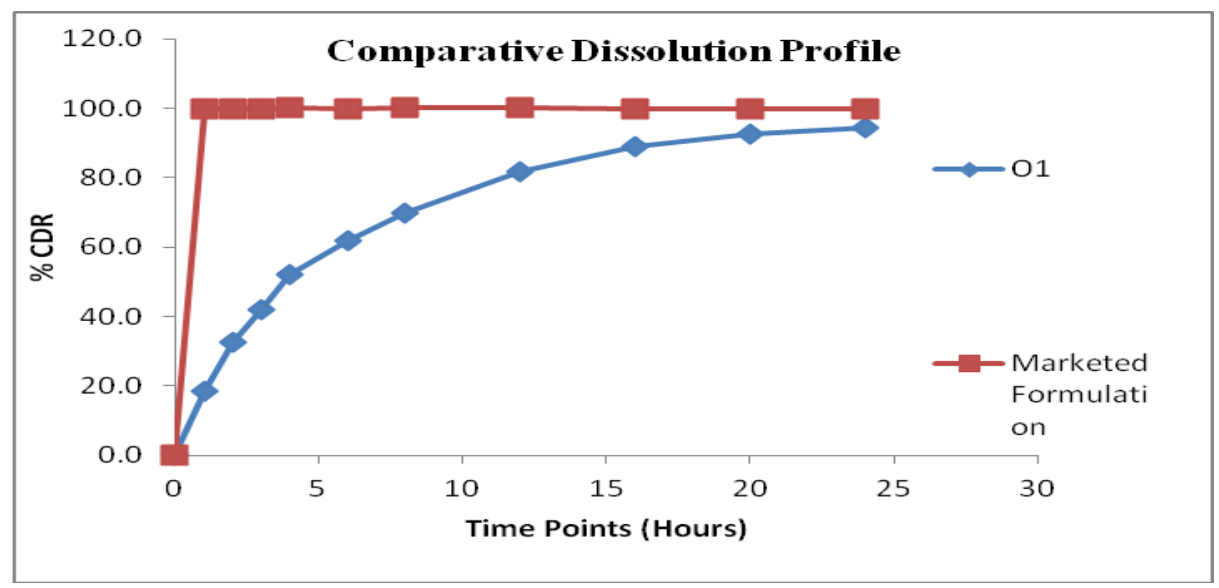

\subsection{Stability Study}

Figure 26: Dissolution Comparison with Marketed Product

Stability study of the final optimized batch was carried out at $40^{\circ} \mathrm{C} / 75 \% \mathrm{RH}$ and the results are tabulated below. Results show that there is no significant change in the formulation after exposing it to high temperature and humidity. Hence, it can be concluded that the final formulation is stable and robust.

Table 29: Stability Study Compilation

\begin{tabular}{|c|c|c|c|}
\hline \multicolumn{4}{|c|}{ Results of Optimized Batch 01} \\
\hline \multirow{2}{*}{\multicolumn{2}{|c|}{\begin{tabular}{|l|} 
Parameters \\
Weight Variation (mg)
\end{tabular}}} & Results & \\
\hline & & $250.6 \pm 4.6$ & $251.2 \pm 5.3$ \\
\hline \multicolumn{2}{|l|}{ Thickness (mm) } & $4.62 \pm 0.05$ & $4.63 \pm 0.07$ \\
\hline \multicolumn{2}{|l|}{ Hardness $\left(\mathrm{kg} / \mathrm{cm}^{2}\right)$} & $15.2 \pm 0.7$ & $16.1 \pm 0.9$ \\
\hline \multicolumn{2}{|l|}{ Friability (\%) } & $0.032 \pm 0.03$ & $0.028 \pm 0.02$ \\
\hline \multicolumn{2}{|l|}{ Drug Content (\%) } & $100.3 \pm 0.2$ & $100.5 \pm 0.4$ \\
\hline \multirow{11}{*}{$\%$ Drug Release } & Time (hours) & $\%$ Drug Release & \\
\hline & 1 & $18.6(8.2)$ & $17.4(7.9)$ \\
\hline & 2 & $32.7(6.9)$ & $31.9(6.8)$ \\
\hline & 3 & $41.8(5.4)$ & $40.9(5.3)$ \\
\hline & 4 & $52.1(3.5)$ & $50.2(4.9)$ \\
\hline & 6 & $61.9(4.4)$ & $59.8(4.1)$ \\
\hline & 8 & $69.8(3.9)$ & $67.3(3.5)$ \\
\hline & 12 & $81.6(3.1)$ & $79.9(2.9)$ \\
\hline & 16 & $88.9(2.2)$ & $87.4(2.5)$ \\
\hline & 20 & $92.7(1.9)$ & $91.3(2.1)$ \\
\hline & 24 & $94.3(1.7)$ & $95.2(1.5)$ \\
\hline
\end{tabular}




\section{CONCLUSION}

Controlled release osmotic tablets of Carvedilol Phosphate were successfully formulated by Direct Compression method and then coating with a semi-permeable membrane such as Cellulose Acetate.

- Preformulation studies of drug were performed; the infrared spectral analysis studies revealed that there is no chemical interaction with excipients used was compatible with drugs.

- Based on Weight variation, Hardness, friability, and Dissolution it was found that all the formulation were satisfactory as per Pharmacopoeial Standards.

- Effect of osmogens, pore forming agent and coating weight gain was studied to evaluate its effect on drug release pattern.

- Marketed formulation showed complete release at first time point, where as Formulation F5 showed best release profile, closest to the desired time period of 24 hours. It also showed Zero order drug release pattern which is ideal for an osmotic drug delivery system.

- A full factorial statistical optimization was carried out on two factors, i.e. Level of Pore former and level of osmogen and evaluates its effect on dissolution. Both factors were found to affect the selected response and the design space was established for both factors.

The final optimized formulation was subjected to Accelerated Stability testing at $40^{\circ} \mathrm{C} / 75 \% \mathrm{RH}$ and was found to be stable for 1 month.

\section{REFERENCES}

1. Jain NK. Progress in controlled and novel drug delivery systems Delhi, CBS Publishers. 2003: 76- 97.

2. Farhan Ahmed, Gaurav. Jain. In Lachman Lieberman's The Theory and Practice of Industrial Pharmacy 4th edition. 2013: 483.

3. Edward Rudnic. In Remington's The Science and Practice of Pharmacy 21st edition. 2005: 893.

4. Brahmankar DM \& Jaiswal SB. Biopharmaceutics and pharmacokinetics a treatise. Vallabh Prakashan, 2008: 337.

5. Sowjanya M, Venkata P, Controlled Releaseinivasa B, Pallavi K, "Osmotic Drug Delivery Systems: A Review", Inventi Rapid: NDDS, 2017, 3: 1-10.

6. Gupta B, Thakur N, Jain N, Ban J, Jain S, "Osmotically controlled drug delivery system with associated drugs." J Pharm Pharmacist Sci, 2010, 13 (3): 571-588,

7. Ratnaparkhi, M. \& Gupta P, "Controled Release Oral Drug Delivery System - An Overview." International Journal of Pharma Research \& Review, 2013, 2(3): 11-21.

8. Khavarel N, Dasankoppa F, Najundaswamy N, "A Review on Key Parameters and Components in Designing of Osmotic Controlled Oral Drug Delivery Systems." Indian Journal of Novel Drug Delivery, 2010, 2(4): 122-126.

9. Parashar B, Maurya B. Yadav V, Sharma L, "A Review on Osmotically Regulated Devices." The Pharma Innovation, 2012, 1(4): 61-69.

10. Single D, Kumar S, Nirmala H, "Osmotic Pump Drug Delivery: A Novel Approach." International Journal of Research in Pharmacy and Chemistry, 2012, 2(2): 661-670.

11. Disease Information: - https://www.mayoclinic.org/diseases-conditions/heart-failure/symptomscauses/syc-20373142.

12. Drug Information: - https://www.drugbank.ca/drugs/DB01136.

13. Drug Information: - https://www.drugbank.ca/salts/DBSALT001201.

14. Drug Information: - https://www.rxlist.com/consumer_Carvedilol Phosphate_coreg_coreg_cr/drugscondition.htm.

15. Drug Information: - https://medlineplus.gov/druginfo/meds/a697042.html.

16. Drug Information: - https://en.wikipedia.org/wiki/Carvedilol Phosphate.

17. Drug Information: - https://www.drugs.com/Carvedilol Phosphate.html.

18. Vidyadhara R, Sasidhar R, Maheswara R, Showri B Lakshmi H, "Formulation and evaluation of verapamil hydrochloride osmotic controlled release matrix tablets", Asian Journal of Pharmaceutics, 2014: 101-109.

19. Hardik P, Patel M, "Formulation and Evaluation of Controlled Porosity Osmotic Drug Delivery System of Carvedilol Phosphate", JPSBR, 2012, 2 (2): 77-82. 
20. Sandhya $P$, Hafsa $S$, Ayesha $S$, Sunitha $M$, Sunil R, "Formulation and Evaluation of Oral Controlled Release Osmotic Tablets of Glimepiride", Journal of Pharmacy and Biological Sciences, 2013, 7 (4): 0107.

21. Falguni S, Hitesh J, Viral K, Umesh U, "Formulation and Evaluation of Controlled Release Osmotic Tablet of Metoprolol Succinate", Asian J Pharm Clin Res, 2014, 7 (3): 38-43.

22. Singla D, Sharma A, Kamboj $H$, Guarve $K$, "Formulation and evaluation of controlled porosity osmotic pump-based tablet of tramadol hydrochloride" Asian Pacific Journal of Health Sciences, 2018, 5 (2): 170-176.

23. Ramu $B$ and Shanmuga $P$, "Formulation and Evaluation of Floating Osmotic Tablets of Nizatidine", Journal of Applied Pharmacy, 2015, 8 (1): 1-7.

24. Poptani S, Gohel M, Parikh R, Patel V, "Preparation and Evaluation of Osmotic Controlled Drug Delivery System of Metoprolol Tartarate", International Bulletin of Drug Research, 2011, 1(1): 84-93.

25. Mehta Tejal, Patel Kunal, "Development and Optimization of Elementary osmotic pump tablet of Nicardipine Hydrochloride using central composite experimental Design", Int. J. Drug Dev. \& Res., 2013, 5 (3): 382-395.

26. Wen J, Ning L, Chong G, "Preparation of controlled porosity osmotic pump tablets for salvianolic acid and optimization of the formulation using an artificial neural network method", Acta Pharmaceutica Sinica $B, 2011,1(1)$ : 64-70.

27. Tiegang $X$, Yang $Z$, Hengpan J, Wenji Z, Yunyun $G$, Xinggang $Y$, Xukai $Q$, Weisan $P$, "A time-released osmotic pump fabricated by compression-coated method: Formulation screen, mechanism research and pharmacokinetic study", Asian Journal of Pharmaceutical Science, 2014, 9: 208-2017.

28. Amish A and Prakash B, "Formulation and evaluation of Carvedilol Phosphate melt-in-mouth tablet using mucoadhesive polymer and PEG-6-stearate as hydrophilic waxy binder," Int J Pharm Investig. 2012, 2 (4): 183-188.

29. Ramana B, Sabiya S, Neelofar S, Spandana D, Parmeswari C and Nagarajan G, "Formulation and evaluation of mucoadhesive matrix tablets of Carvedilol Phosphate", Der Pharmacia Lettre, 2014, 6 (6): 257-265.

30. Vilas G, Shashidhar S, Umesh S, "Formulation and Evaluation of Immediate Release Tablet of Carvedilol Phosphate using Liquisolid Compacts Technique for Solubility Enhancement", Asian Journal of Pharmaceutics, 2016, 10 (3): 1-9.

31. Sugeuna Venkata Ratnam, Debjit Bhowmik, Rajbahadur Yadav, Devdatta Singh, "Formulation And Evaluation of Carvedilol Phosphate Fast Dissolving Tablets", Journal of Chemical and Pharmaceutical Sciences, 2014, 7 (2): 85-89.

32. Rania H, Areeg A, Suhair S, Ola T, Sami N, Tamadur A, Jihan A and Aiman A, "pH-Dependent Solubility and Dissolution Behavior of Carvedilol Phosphate-Case Example of a Weakly Basic BCS Class II Drug", AAPS Pharm Sci Tech, 2016, 17 (2): 418-426.

33. Jaimin J, Ravi R, Patel L, Yogesh P and Anil R, "Formulation and Evaluation of Time Delayed Release Tablet of Carvedilol Phosphate", Pharmacophore, 2016, 7 (2): 124-131.

34. Joshi P., Patel M, Patel K, Patel N, "Design and Development of Carvedilol Phosphate Floating Microsphere", International Journal of Pharmamedix, 2013, 1 (4): 557-71.

35. Chatterjee $B, P a l K$, "Development and in vitro evaluation of micronized sustained release matrix tablet of Carvedilol Phosphate", Int J Pharm Sci Res, 2010, 1: 96-102.

36. Rania H, Areeg A, Suhair S, Ola T, Sami N, Tamadur A, Jihan S, Aiman A, "pH-Dependent Solubility and Dissolution Behaviour of Carvedilol Phosphate-Case Example of a Weakly Basic BCS Class II Drug", AAPS PharmSciTech, 2015, 17(2): 418-426.

37. Verma K, Garg S, "Development and evaluation of osmotically controlled oral drug delivery system of glipizide", European Journal of Pharmaceutics and Biopharmaceutics, 2004, 57: 513-525.

38. Rajewski A, "Applicability of (SBE) $7 \mathrm{~m} \beta-\mathrm{CD}$ in controlled-porosity osmotic pump tablets (OPTs)", International Journal of Pharmacy, 2004, 286: 81-88.

39. Kanagale $P$, Lohray B, Mishra A, Davadra P, Kini R, "Formulation and optimization of porous pumpbased controlled release system of oxybutynin", American Association of Pharmaceutical Scientists Technology, 2007, 8(3): 1-7. 
40. Ramakrishna N, Mishra B, "Plastizer effects and comparative evaluation of cellulose acetate and ethyl cellulose-HPMC combination coating as semi-permeable membrane for oral osmotic pump of naproixen sodium", Drug Dev Ind Pharm, 2002, 28: 403-12.

41. Ritschel $A$, "Biopharmaceutic and pharmacokinetic aspects in the design of controlled release per-oral drug delivery systems", Drug Dev Ind Pharm, 1989, 15: 1073-1103.

42. Sheskey P, Pacholke K, Sackett G, Maher L, Polli J, "Roll compaction granulation of a controlled release matrix tablet formulation containing HPMC: Effect of process scale-up on robustness of tablets, tablet stability and predicted in vivo performance", Pharm Technol, 2000, 24: 30-52.

43. Chen $C$, Lee $D$, Xie J, "Controlled release formulation for water insoluble drugs in which a passageway is formed in situ" US patent 5736159, 1998.

44. Suvakantha D, "Kinetic modeling on drug release from controlled drug delivery systems", Acta Poloniae Pharmaceutical Drug Research,2010, 67: 217- 223.

Liu L, Wang X, "Solubility modulated monolithic osmotic pump tablet for atenolol delivery", Eur. J. Pharm Biopharm, 2008, 68(2): 298-302 